\title{
Combined Treatment With Environmental Enrichment and (-)-Epigallocatechin-3-Gallate Ameliorates Learning Deficits and Hippocampal Alterations in a Mouse Model of Down Syndrome
}

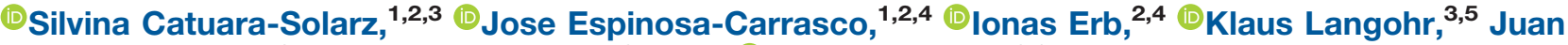 \\ Ramon Gonzalez, ${ }^{6,7}$ Cedric Notredame, ${ }^{2,4}$ and ${ }^{-}$Mara Dierssen ${ }^{1,3,8}$
}

DOI:http://dx.doi.org/10.1523/ENEURO.0103-16.2016

${ }^{1}$ Cellular and Systems Neurobiology, Systems Biology Program, the Barcelona Institute of Science and Technology, Centre for Genomic Regulation (CRG), 08003, Barcelona, Spain, '2Universitat Pompeu Fabra (UPF), Barcelona, 08003, Spain, ${ }^{3}$ Human Pharmacology and Clinical Neurosciences Research Group, Neurosciences Research Program, Hospital Del Mar Medical Research Institute (IMIM), Barcelona, 08003, Spain, ${ }^{4}$ Comparative Bioinformatics, Bioinformatics, and Genomics Program, Barcelona Institute of Science and Technology, Centre for Genomic Regulation, Barcelona, 08003, Spain, ${ }^{5}$ Department of Statistics and Operations Research, Universitat Politècnica De Catalunya/BarcelonaTech, Barcelona, 08034, Spain, ${ }^{6}$ Centre for Research in Environmental Epidemiology, Barcelona, 08003, Spain, ${ }^{7}$ Centro De Investigación Biomédica En Red De Epidemiología Y Salud Pública, Madrid, 28029, Spain, and ${ }^{8}$ Centro De Investigación Biomédica En Red De Enfermedades Raras, Madrid, 28029, Spain

\section{Visual Abstract}

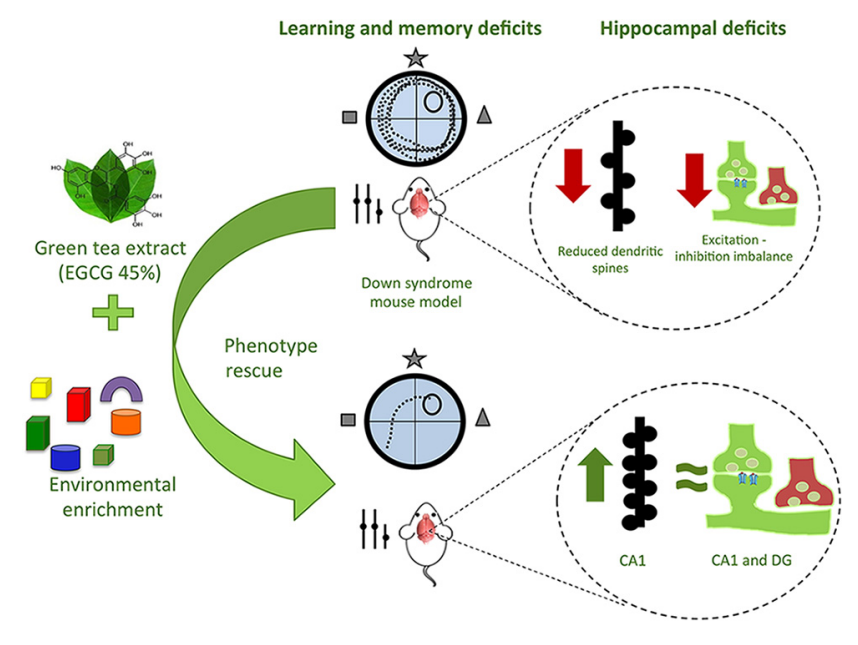

\section{Significance Statement}

Therapeutic methods for improving intellectual disability in Down syndrome (DS) are limited, and their outcome remains unsatisfactory. Recently, we demonstrated that combined treatment with (-)-epigallocatechin-3-gallate (EGCG) and cognitive stimulation rescued cognitive deficits in DS individuals in a phase II clinical trial and also in a middle-age Ts65Dn mouse model of DS. Here, we show that environmental enrichment (EE) plus EGCG treatment improves corticohippocampal-dependent learning and memory deficits in young trisomic mice, restores cornu ammonis 1 (CA1) hippocampal dendritic spine density, and mitigates disruptions in excitatory/inhibitory synaptic puncta in CA1 and dentate gyrus. Our results suggest that therapies with the capacity to simultaneously target several abnormal processes underlying intellectual disability and use physiologic plasticity-enhancing interventions such as EE are optimal for disease-modifying interventions. 
Intellectual disability in Down syndrome (DS) is accompanied by altered neuro-architecture, deficient synaptic plasticity, and excitation-inhibition imbalance in critical brain regions for learning and memory. Recently, we have demonstrated beneficial effects of a combined treatment with green tea extract containing (-)-epigallocatechin3-gallate (EGCG) and cognitive stimulation in young adult DS individuals. Although we could reproduce the cognitive-enhancing effects in mouse models, the underlying mechanisms of these beneficial effects are unknown. Here, we explored the effects of a combined therapy with environmental enrichment (EE) and EGCG in the Ts65Dn mouse model of DS at young age. Our results show that combined EE-EGCG treatment improved corticohippocampal-dependent learning and memory. Cognitive improvements were accompanied by a rescue of cornu ammonis 1 (CA1) dendritic spine density and a normalization of the proportion of excitatory and inhibitory synaptic markers in CA1 and dentate gyrus.

Key words: (-)-epigallocatechin-3-gallate; Down syndrome; environmental enrichment; excitation-inhibition imbalance; neuroplasticity

\section{Introduction}

Down syndrome (DS) is the most common genetic form of intellectual disability, with $\sim 10$ in 10,000 and 14 in 10,000 live births in European countries (Khoshnood et al., 2011) and the United States (Parker et al., 2010), respectively. It arises from the presence of an extra copy (or major portion) of chromosome 21 (Hsa21), leading to a complex genetic imbalance (Antonarakis et al., 2004). Individuals with DS show moderate to severe cognitive impairment, with an average intellectual quotient of 40-50 (de Sola et al., 2015) and 39.4\% in the mild intellectual disability range of $50-70$. The neuropsychological profile is characterized by marked hippocampal-dependent deficits particularly affecting spatial learning, memory, and executive functions, among other cognitive domains (Chapman and Hesketh, 2000; Nadel, 2003; Pennington et al., 2003). These cognitive deficits are associated with distinct neuro-architectural, synaptic, and neurochemical alterations (Lott and Dierssen, 2010; Dierssen, 2012). At the cellular level, there is a reduction in dendritic number and complexity in cortical and hippocampal neurons, which affects synaptic connectivity (Becker et al., 1986). Furthermore, accumulating evidence suggest that DS

Received May 2, 2016; accepted September 8, 2016; First published October 19, 2016.

Authors report no conflict of interest.

Authors Contribution: S.C.S. designed research, performed research, analyzed data, wrote the paper; J.E.-C., I.E., K.L., J.R.G. analyzed data; C.N. supervised the PCA analysis; M.D. provided financial support, designed research, wrote the paper.

This research was supported by DIUE of Generalitat de Catalunya (Grups consolidats SGR 2014/1125); Fondation Jérôme Lejeune (Paris, France); Spanish Ministry of Economy and Finance (MINECO) grants SAF2013-49129C2-1-R, BFU2011-28575, and MTM2015-64465-C2-1-R CDTI ("Smartfoods"); the CIBER of Rare Diseases (ISCIII initiative); and EU-Era Net Neuron PCIN2013-060. The CRG has received support as a Severo Ochoa Center of Excellence SEV- 2012-O208. S.C.-S. received a FPI doctoral Fellowship from the MINECO (SAF2010-16427).

Acknowledgments: We gratefully thank the students Carla Cuní-Lopez, Andrea Pérez, and María Alemany for their contribution in data acquisition and technical assistance.

Correspondence should be addressed to M. Dierssen, Cellular and Systems Neurobiology, Systems Biology Program, Centre for Genomic Regulation, Dr. Aiguader 88, 08003 Barcelona, Spain. E-mail: mara.dierssen@crg.eu.

DOl:http://dx.doi.org/10.1523/ENEURO.0103-16.2016

Copyright $\odot 2016$ Catuara-Solarz et al.

This is an open-access article distributed under the terms of the Creative Commons Attribution 4.0 International, which permits unrestricted use, distribution and reproduction in any medium provided that the original work is properly attributed. pathophysiology is tightly associated with a disruption of the balance between the excitatory and inhibitory neuronal systems (Reynolds and Warner, 1988; Risser et al., 1997; Seidl et al., 2001; Bhattacharyya et al., 2009). These abnormalities are of particular importance because they are related to disruptions in neural plasticity, which is essential for cognition (Baroncelli et al., 2011).

Several research groups have shown that it is possible to partially rescue DS phenotypes using nonpharmacological strategies such as postnatal handling or cognitive training by environmental enrichment (EE) that ameliorate behavioral and brain alterations in the Ts65Dn mouse model of DS (Martínez-Cué et al., 2002; Dierssen, 2003; Begenisic et al., 2011; Chakrabarti et al., 2011; Golabek et al., 2011). It is widely accepted that EE is a cognitive enhancing intervention that promotes synaptic plasticity, adult neurogenesis, and epigenetic modifications, among other processes (Sale et al., 2014). However, despite its beneficial effects, EE is not sufficient to promote longlasting dendritic spine remodeling in Ts65Dn mice (Dierssen, 2003) or significant developmental changes in DS children (Mahoney et al., 2004).

More recently, (-)-epigallocatechin-3-gallate (EGCG), the most abundant catechin found in green tea, with antioxidant and neuroprotective properties, has been shown to efficiently improve cognitive phenotypes in DS individuals and mouse models (De la Torre et al., 2014), ameliorate synaptic plasticity impairment in vitro (Xie et al., 2008), and restore excitatory/inhibitory (E/I) imbalance in Ts65Dn mice (Souchet et al., 2015). EGCG is a natural inhibitor of the kinase activity of Hsa21 candidate gene Dyrk1A (Bain et al., 2003), whose overexpression is sufficient to induce cognitive and neuromorphologic alterations (Altafaj et al., 2001; Martinez de Lagran et al., 2012) and that is also modulated by EE (Golabek et al., 2011; Pons-Espinal et al., 2013). Recently, we showed that combined treatment with EE and EGCG is more efficient than EE or EGCG alone to ameliorate age-associated cognitive impairment of older Ts65Dn mice (CatuaraSolarz et al., 2015), suggesting a synergistic mechanism. Furthermore, we demonstrated that combined treatment with cognitive training and EGCG is more efficient than cognitive training alone to promote cognitive enhancement as well as neurophysiological recovery in young adults with DS in a phase II clinical trial (de la Torre et al., 2016). Thus, here we explored the effects of combined 
EE-EGCG treatment on hippocampal cognitive, neuronal, and synaptic alterations in young adult Ts65Dn mice.

\section{Materials and Methods}

\section{Animals}

Ts65Dn (TS) and wild-type (WT) littermates were obtained through crossings of B6EiC3Sn a/A-Ts $\left(17^{16}\right) 65 \mathrm{Dn}$ (Ts65Dn) females to B6C3F1/J males purchased from the Jackson Laboratory (Bar Harbor, ME; RRID:IMSR_JAX: 001924). The mouse colony was bred in the Animal Facilities of the Barcelona Biomedical Research Park (PRBB, Barcelona, Spain). Mice were housed in standard or enriched conditions (see below) under a 12:12-h light: dark schedule (lights on at 8:00 a.m.) in controlled environmental conditions of humidity $(60 \%)$ and temperature $\left(22^{\circ} \mathrm{C} \pm 2^{\circ} \mathrm{C}\right)$ with ad libitum access to food and water. Both the Ts65Dn and euploid mice were genotyped by quantitative PCR, in accordance with the Jackson Laboratory protocol.

Experiments were conducted using 1- to 2-month-old female mice. We used females because in EE conditions, Ts65Dn males show high levels of stress that could mask the effect of the treatment (Martínez-Cué et al., 2002). Although the estrus cycle may be slightly delayed in Ts65Dn mice, by the age of 2 months it is synchronized among all females (including Ts65Dn and euploid mice; Netzer et al., 2010). Thus, for the experiments conducted in this study, it is unlikely that variations in estrogen levels between mice could influence behavior, spine density, or E/I balance.

All animal procedures met the guidelines of European Community Directive 2010/63/EU and local guidelines (Real Decreto 53/2013) and were approved by the local ethics committee (Comité Ético de Experimentación Animal del PRBB; procedure numbers MDS-08-1060P2 and MDS-14-1611).

\section{EE and EGCG}

Ts65Dn and WT 1- to 2-month-old female mice were assigned using a simple randomization to either control conditions or a combination of EE and green tea extracts containing 45\% EGCG. Mice received the treatments for 30 days based on previous studies (De la Torre et al., 2014; Catuara-Solarz et al., 2015). In the control conditions, animals were reared in conventional Plexiglas cages (20 $\times 12 \times 12$-cm height) in groups of $2-3$ animals. EE housing consisted of spacious (55 × $80 \times 50-\mathrm{cm}$ height) cages with toys, small houses, tunnels, and platforms of different shapes, sizes, colors, and textures. Wheels were not introduced in the cages to avoid the effect of physical exercise. The arrangement was changed every 2 days to keep novelty conditions. To stimulate social interactions, 6-8 mice were housed in each cage. Green tea extract containing 45\% EGCG was administered in drinking water (EGCG dosage: $0.326 \mathrm{mg} / \mathrm{ml}, 0.65 \mathrm{mg}$ per day; $30 \mathrm{mg} / \mathrm{kg}$ per day) by preparing fresh EGCG solution every 2 days from a green tea leaf extract (Mega Green Tea Extract, Decaffeinated, Life Extension, Fort Lauderdale, FL; EGCG content $326.25 \mathrm{mg}$ per capsule).

\section{Morris water maze}

The Morris water maze (MWM) was performed according to a previously described method (Catuara-Solarz et al., 2015). Briefly, mice were trained in a water maze (pool, 1.70-m diameter; platform, 12-cm diameter) during five learning sessions (four acquisition trials per session and one session per day). Twenty-four hours after the final acquisition session, mice underwent one probe/removal session (reference memory trial) in which the platform was removed, followed by one cued session. Starting the next day, three reversal sessions (four trials per session) were conducted in which the platform position was changed $180^{\circ}$ to test cognitive flexibility as a measure of executive function. In every session, mice randomly entered the pool from four different positions and were allowed to search the platform for $60 \mathrm{~s}$. The experimenter who performed all the MWM procedures was blind to mice genotype. Mice were video-tracked during the test, and their latency to reach the platform, total distance swum, time spent in periphery, and swimming speed were recorded using SMART software (Panlab, Barcelona, Spain, RRID: SCR_002852). Subsequently, data were computed with software developed by our lab (Jtracks; Arqué et al., 2008) to obtain other measurements to quantify the most efficient and direct trajectory from the location of mice to the platform, such as the Gallagher index (average distance from each mouse to the center of the platform), the Gallagher distance (accumulated distance from each mouse to the center of the platform), and the Whishaw index (percentage of path inside the optimal corridor connecting release site and goal; Whishaw and Jarrard, 1996). Mice that did not reach the platform in $<30 \mathrm{~s}$ in the cue session were considered unsuitable for the test and were subtracted from the analysis. One overperforming mouse from the EE-EGCG-treated TS group was removed from the analysis. The estimate of the number of mice required ( $n=10$ ) was based on the expected difference between the experimental groups, deriving from previous data obtained in our laboratory (WT, $n=11$; TS, $n=8$; WT-EEEGCG, $n=12$; TS-EE-EGCG, $n=8$ ).

\section{Novel object recognition test}

The novel object recognition test was performed as an adaptation from the protocols described in Leger et al. (2013). The procedure was conducted in a V-maze apparatus (wall height $27 \mathrm{~cm}$, arm length $30 \mathrm{~cm}$, and arm width $6 \mathrm{~cm}$ ). First, mice were subjected to a 5-min habituation session during which they were allowed to explore the maze without any objects. The next day, mice went through a 10-min familiarization session in which two identical objects were situated at the end of each arm attached to the wall and the floor with adhesive tape. After a 60-min intertrial interval, the recognition test session was conducted consisting of a 5-min trial in which one of the objects used at familiarization was substituted by a new object. Recognition of the new object was assessed by calculating the discrimination index (DI) by the following formula DI = (novel object exploration time/total exploration time) - (familiar object exploration time/total exploration time) $\times 100$. Exploratory behavior was defined 
as the mouse directing its head or sniffing toward the object at a distance of $\sim 1-2 \mathrm{~cm}$. The estimate of the sample size was based on previous data obtained in our laboratory (WT, $n=8$; TS, $n=7$; WT-EE-EGCG, $n=7$; TS-EE-EGCG, $n=7$ ).

\section{Golgi neuronal staining and dendritic spine imaging}

To avoid confounding effects, these experiments were performed with mice that did not undergo behavioral assessment. Golgi staining was performed according to manufacturer instructions (SuperGolgi Kit, Bioenno Tech, Santa Ana, CA; cat. \# 003010, RRID:AB_2620135). Mice were sacrificed with $\mathrm{CO}_{2}$ and perfused intracardially with $0.01 \mathrm{M}$ PBS followed by chilled $4 \%$ paraformaldehyde (PFA). Brains were removed from the skull and hemispheres were immersed freshly into impregnation solution for 9 days. When impregnation was ready, tissue blocks were rinsed with distilled water and transferred into postimpregnation buffer for 4-5 days at room temperature (RT) in the dark. The solution was renewed after 1 day of immersion. After that, brains were cut with a vibratome (VT1000S; Leica Microsystems, Wetzlar, Germany) in sections of $150 \mu \mathrm{m}$ and kept in collection and mounting buffer. Sections were mounted on adhesive microscope slides, and gentle pressure was applied with filter paper over the sections to enhance adhesion. Slides were washed in $0.01 \mathrm{M}$ PBS/0.3\%Triton X-100 for 20-30 min and placed in the staining solution for $20 \mathrm{~min}$ in a closed dark jar. After that, slides were moved to the poststaining buffer for $20 \mathrm{~min}$ in a dark area and washed in $0.01 \mathrm{M}$ PBS/0.3\% Triton X-100 for 15 min. Slides were dried in a closed jar at RT for $1 \mathrm{~d}$. Finally, sections were dehydrated in $100 \%$ ethanol for $5-10$ min and cleared in xylene for another $10 \mathrm{~min}$. Slides were covered with coverslips using mounting medium and were kept at RT in a dark area.

Images were acquired from outer molecular layer secondary apical dendrites of granule neurons (located $40-90 \mu \mathrm{m}$ from the neuronal soma) of the dentate gyrus (DG) and secondary apical dendrites from pyramidal neurons from the cornu ammonis 1 (CA1; located 50-100 $\mu \mathrm{m}$ from the neuronal soma). These hippocampal regions were selected because they play a critical role in the process and storage of spatial information (Tsien et al., 1996; Deng et al., 2010). We used an Olympus BX51 microscope with $100 \times$ objective and Neurolucida software (11.03.1, MBF Bioscience, Williston, VT; RRID: SCR_001775). Quantification of dendritic spine density was performed on $20-\mu \mathrm{m}$ dendritic segment lengths using $\mathrm{NIH}$ ImageJ software version 1.46a and Multipoint plugin. The criterion to define dendritic spines was the identification of tridimensional protrusions emerging from the dendritic shaft that could be visualized across the $z$-planes. For this experiment, we used three brain slices per mouse of the dorsal hippocampus (bregma: 1.82-1.94, Paxinos and Franklin, 2012) of five to six mice per experimental group. From each brain slice, two to three dendrites from each hippocampal subregion were imaged (number of dendrites in DG: WT, 46; TS, 42; WT EE-EGCG, 48; TS
EE-EGCG, 42; number of dendrites in CA1: WT, 38; TS, 32; WT EE-EGCG, 31; TS EE-EGCG, 39).

\section{Immunohistochemical labeling of excitatory and inhibitory synaptic vesicle proteins}

Synaptic modifications due to genotype and treatment were addressed by performing immunohistochemical labeling for vesicular glutamate transporter 1 (VGLUT1) and vesicular GABA transporter (VGAT). Animals were exposed to $\mathrm{CO}_{2}$ and afterward perfused intracardially with $0.01 \mathrm{~m}$ PBS, $\mathrm{pH} 7.5$, followed by $4 \%$ PFA. Brains were removed, kept at $4^{\circ} \mathrm{C}$ in $4 \%$ PFA overnight, and transferred to a solution of $30 \%$ sucrose in PBS for 2 days. Series of coronal sections $(40 \mu \mathrm{m})$ were obtained using a vibratome (VT1000S; Leica Microsystems) and stored at $-20^{\circ} \mathrm{C}$ in a cryoprotection solution (30\% ethylene glycol, $30 \%$ glycerol, $40 \%$ PBS). Free-floating brain sections were permeabilized with $0.3 \%$ Triton X-100 in PBS for 30 min at RT and incubated for 20 min with Glycine (50 mM) in PBS $/ 0.3 \%$ Triton $X-100$. Slices were washed for $15 \mathrm{~min}$ with PBS $/ 0.3 \%$ Triton X-100 and blocked with $5 \%$ normal goat serum (NGS)/PBS/-0.3\% Triton X-100 for $1 \mathrm{~h}$ at RT. Sections were incubated overnight at $4^{\circ} \mathrm{C}$ with the primary antibodies-mouse anti-VGLUT1 monoclonal antibody (1: 150; cat. no. 135-511, Synaptic Systems, Goettingen, Germany; RRID: AB_887879) and guinea pig anti-VGAT polyclonal antibody (1:200; cytoplasmic domain; Synaptic Systems; cat. no. 131004, RRID:AB_887873)—in 0.1\% Triton X-100/2.5\% NGS in PBS. Slices were washed with PBS/0.3\% Triton X-100 and incubated with secondary antibodies-Alexa Fluor 488 goat anti-mouse (cat. no. A11001, RRID:AB_2534069) and Alexa Fluor 555 antiguinea pig (cat. no. A-21435, RRID:AB_2535856; 1:1000-in 0.1\% Triton X-100/2.5\% NGS in PBS for $2 \mathrm{~h}$ at RT, protected from light. Finally, sections were washed with PBS $/ 0.3 \%$ Triton X-100, nuclei were stained with Hoechst (1:1000) in PBS for $10 \mathrm{~min}$, and tissues were mounted on glass slides with Mowiol reagent.

Images were acquired from DG and CA1 hippocampal regions using a confocal microscope with a $63 \times$ objective (TCS SP5, Leica Microsystems) and LAS AF software. For each region, all pictures were captured with identical confocal settings for laser power, gain, and offset levels. Images were imported into ImageJ, converted into binary data, and thresholded to achieve maximum number of individual puncta without causing puncta fusion. The same threshold was applied to all the images to outline puncta number, size, and percentage of area occupied by puncta, using the "analyze particle" plugin. For this experiment, we used two brain slices of the dorsal hippocampus (bregma: 1.82-1.94, Paxinos and Franklin, 2012) of four mice per experimental group. From each brain slice, four to five images were acquired per hippocampal subregion.

\section{Statistical analysis}

\section{Morris water maze}

Single-variate analysis

Differences among experimental groups over time were tested using a single-variate analysis for selected 
learning-related parameters (latency to reach the platform, Gallagher index, and percentage of time spent in the periphery) using one-way repeated-measures ANOVA. To avoid the ceiling effect of mice unable to solve the task, the variable latency was considered right-censored when reaching the maximum allowed time $(60 \mathrm{~s}$; Vock et al., 2012) using a Tobit model implemented in the censReg package from $\mathrm{R}$ Foundation for Statistical Computing (RRID:SCR_001905), version 3.2.1 (Henningsen, 2011). Multiple comparisons for parametric models were used to address post hoc comparisons using the multtest $R$ package and the glht function (Hand and Taylor, 1987; Dickhaus, 2012). To control the FDR caused by multiple post hoc comparisons, the Benjamini-Hochberg method was used (Benjamini and Hochberg, 1995).

\section{Principal component analysis}

We used principal component analysis (PCA) to identify the linear combinations of the original variables (latency to reach the platform, percentage of time spent in target quadrant, percentage of time spent in the periphery, Whishaw index, Gallagher index, distance traveled, and speed) that explain the maximum amount of experimental variability. More precisely, our application of the method aims primarily at two kinds of variability: variation among experimental groups for a given learning session and variation of a given group across learning sessions. For this, we implemented the same procedure as described in Catuara-Solarz et al. (2015). Briefly, a PCA for the acquisition sessions was performed on 20 observations of seven variables. Here, the observations correspond to the four experimental groups on the five learning sessions, and the variables are the experimental parameters described above. The resulting $20 \times 7$ data matrix contains the medians of the measured variables for each group during each session (the four trials per mouse of each learning session were averaged). As variables are measured in different units, they were scaled to unit variance to enable a combined analysis. The result of the described PCA approximates a decomposition of what is commonly called between-group variance. A third kind of variability coming from individuals within a group for a given session can also be quantified. For this, 195 supplementary points that correspond to the 39 individuals appearing five times each were projected. The $R$ package FactoMineR was used (Lê et al., 2008). Separately, a similar PCA was done for the three reversal sessions.

Our analysis can be considered a discriminant analysis in the sense that the PCA is performed for groups and individuals are projected only after the PCA is performed. However, we use group medians instead of the commonly applied group means weighted by group sizes, leading to two differences: first, between-group variance is defined as variance between group medians; second, the overall barycenter no longer coincides with the group barycenter (our origin), and thus the total variance obtained by summing squared distances of all individuals from the origin as applied in Catuara-Solarz et al. (2015) overestimates the true variance by a small amount (i.e. by the squared distance of the barycenter from the origin). To comply with the original definition (Greenacre, 2010, chapter 11) of between-group variance when decomposing total variance, the overall barycenter instead of the origin can be used as the reference point, and weighted group means obtained from the supplementary points can be used to calculate the between-group variance instead. We found that the difference between the two approaches is on the order of a few percentage points only.

To validate the stability of the PCA, we used a jackknifing procedure: each individual is subtracted from the analysis, the resulting modified group median is used to perform a new PCA, and the angle between the new first principal component (PC1) and PC2 with respect to the original principal axes is computed. The procedure showed that both axes remain very stable, with PC1 attaining maximum angles around 1 degree, suggesting a minor influence of the small number of experimental groups on the outcome of the analysis (data not shown).

Density plots were obtained using the statdensity_2d function from the ggplot2 R package (Wickham, 2009; RRID:SCR_014601) with the parameters: $n=100, \mathrm{~h}=4$, and bins $=6$. to assess statistical significance of group separation, we randomly reassigned individuals to experimental groups to perform a permutation test (Sham and Purcell, 2014) in which original numbers of individuals in each group were kept. For this, learning differences were evaluated using a $t$ statistic involving PC1 pairwise group comparisons based on supplementary points. All pairwise comparisons were determined at each permutation. The number of randomized PCAs was 10,000. Finally, to evaluate the change in within-group variances before and after learning, we averaged squared distances of a group's supplementary points from their barycenter using coordinates from all seven principal axes.

\section{Novel object recognition}

Differences in the discrimination index among experimental groups were tested using one-way ANOVA. Tukey multiple comparisons for parametric models were used to address post hoc comparisons using the multtest $R$ package and the glht function (Hand and Taylor, 1987; Dickhaus, 2012). To control the FDR caused by multiple post hoc comparisons, the Benjamini-Hochberg method was used (Benjamini and Hochberg, 1995).

\section{Dendritic spine density and excitatory (VGLUT1) and inhibitory (VGAT) synaptic puncta}

For analysis of the differences among the experimental groups in dendritic spine densities and number, size, and percentage of area occupied by synaptic puncta of VGLUT1 and VGAT, we used linear mixed models, which included experimental group as a factor and mouse as a random effect to account for the repeated measures per mouse. The $F$ test was used to evaluate the global hypothesis that there was no association between the response variables and the groups. Whenever this hypothesis was rejected, post hoc tests for the following contrasts of interest were applied: WT versus TS; TS versus TS EE-EGCG, and WT versus WT-EE-EGCG. The analyses were performed using $\mathrm{R}$ packages nlme (Pinheiro et al., 2016) and multcomp (Hothorn et al., 2008) for the fit of the linear mixed models and the multiple tests, 
Table 1. Single-variate MWM multiple post hoc comparisons with Benjamini-Hochberg correction.

\begin{tabular}{|c|c|c|c|c|c|c|c|c|c|c|}
\hline \multirow[b]{2}{*}{ Figure } & \multirow[b]{2}{*}{ Variable } & \multirow[b]{2}{*}{ Phase } & \multirow[b]{2}{*}{ Contrast } & \multirow[b]{2}{*}{ Data structure } & \multirow[b]{2}{*}{ Type of test } & \multirow{2}{*}{$\begin{array}{l}\text { Estimated mean } \\
\text { difference }\end{array}$} & \multirow[b]{2}{*}{ SE } & \multicolumn{2}{|c|}{$\begin{array}{l}\text { 95\% confidence } \\
\text { interval }\end{array}$} & \multirow[b]{2}{*}{$p$-value } \\
\hline & & & & & & & & Lower & Higher & \\
\hline Fig. 1B & Latency & $A C Q$ & Overall effect & Continuous variable & Tobit model & $\chi_{(3)}^{2}=42.24$ & & & & $<0.001$ \\
\hline Fig. 1B & Latency & $A C Q$ & TS_WT & Continuous variable & Tobit model & 51.262 & 11.28 & 29.146 & 73.377 & $<0.001$ \\
\hline Fig. 1B & Latency & $A C Q$ & TS EE-EGCG_TS & Continuous variable & Tobit model & -23.839 & 12.98 & -49.280 & 1.602 & 0.028 \\
\hline Fig. 1B & Latency & $A C Q$ & TS EE-EGCG_WT & Continuous variable & Tobit model & 27.423 & 11.40 & 5.066 & 49.780 & 0.005 \\
\hline Fig. 1C & Gallagher distance & $A C Q$ & Overall effect & Continuous variable & ANOVA repeated-measures $F$-test & $F=13.636$ & & & & $<0.001$ \\
\hline Fig. $1 \mathrm{C}$ & Gallagher distance & $A C Q$ & TS_WT & Continuous variable & ANOVA repeated-measures $F$-test & 1903.3 & 397.6 & 1124 & 2682.6 & $<0.001$ \\
\hline Fig. $1 \mathrm{C}$ & Gallagher distance & $A C Q$ & TS EE-EGCG_TS & Continuous variable & ANOVA repeated-measures $F$-test & -896.3 & 427.9 & -1734.9 & -57.6 & 0.043 \\
\hline Not shown & Gallagher index & $A C Q$ & Overall effect & Continuous variable & ANOVA repeated-measures $F$-test & $F=10.226$ & & & & $<0.001$ \\
\hline Not shown & Gallagher index & $A C Q$ & TS _WT & Continuous variable & ANOVA repeated-measures $F$-test & 17.217 & 3.981 & 9.41424 & 25.01976 & $<0.001$ \\
\hline Not shown & Gallagher index & $A C Q$ & TS EE-EGCG_TS & Continuous variable & ANOVA repeated-measures $F$-test & -8.903 & 4.284 & -17.2996 & -0.50636 & 0.045 \\
\hline Fig. 1D & Thigmotaxis & $A C Q$ & Overall effect & Continuous variable & ANOVA repeated-measures $F$-test & $F=9.22$ & & & & $<0.001$ \\
\hline Fig. 1D & Thigmotaxis & $A C Q$ & TS_WT & Continuous variable & ANOVA repeated-measures $F$-test & 21.172 & 5.629 & 10.13916 & 32.20484 & $<0.001$ \\
\hline Fig. 1D & Thigmotaxis & $A C Q$ & TS EE-EGCG_TS & Continuous variable & ANOVA repeated-measures $F$-test & -11.374 & 6.057 & -23.2457 & 0.49772 & 0.09 \\
\hline Not shown & Speed & $A C Q$ & Overall effect & Continuous variable & ANOVA repeated-measures $F$-test & $F=4.883$ & & & & 0.006 \\
\hline Not shown & Speed & $A C Q$ & TS_WT & Continuous variable & ANOVA repeated-measures $F$-test & -4.547 & 1.354 & -7.20084 & -1.89316 & 0.004 \\
\hline Not shown & Speed & $A C Q$ & TS_TS EE-EGCG & Continuous variable & ANOVA repeated-measures $F$-test & 1.725 & 1.457 & -1.13072 & 4.58072 & 0.28 \\
\hline Not shown & Speed & $A C Q$ & WT EE-EGCG_WT & Continuous variable & ANOVA repeated-measures $F$-test & -0.485 & 1.216 & -2.86836 & 1.89836 & 0.69 \\
\hline Fig. $1 \mathrm{E}$ & Latency first entry & REM & TS_WT & Continuous variable & One-way ANOVA & 25.284 & 7.295 & 10.9858 & 39.5822 & 0.004 \\
\hline Fig. $1 \mathrm{E}$ & Latency first entry & REM & TS EE-EGCG_TS & Continuous variable & One-way ANOVA & -16.075 & 7.850 & -31.461 & -0.689 & 0.096 \\
\hline Fig. 1F & Latency first entry & REM & Overall effect & Continuous variable & One-way ANOVA & $F=6.159$ & & & & 0.002 \\
\hline Fig. $1 \mathrm{~F}$ & Gallagher index & REM & TS_WT & Continuous variable & One-way ANOVA & 17.991 & 7.041 & 4.19064 & 31.79136 & 0.03 \\
\hline Fig. $1 \mathrm{~F}$ & Gallagher distance & REM & TS_WT & Continuous variable & One-way ANOVA & 1272.4 & 455.5 & -437.28 & 2165.18 & 0.025 \\
\hline Fig. $1 \mathrm{~F}$ & Gallagher index & REM & TS EE-EGCG _TS & Continuous variable & One-way ANOVA & -11.944 & 7.577 & -26.7949 & 2.90692 & 0.14 \\
\hline Fig. $1 \mathrm{G}$ & Latency & REV & Overall effect & Continuous variable & Tobit model & $\chi_{(3)}^{2}=26.59$ & & & & $<0.001$ \\
\hline Fig. $1 \mathrm{G}$ & Latency & REV & TS_WT & Continuous variable & Tobit model & 35.093 & 9.16 & 17.124 & 53.063 & $<0.001$ \\
\hline Fig. 1G & Latency & REV & TS EE-EGCG_TS & Continuous variable & Tobit model & -14.865 & 9.28 & -33.073 & 3.342 & 0.060 \\
\hline Fig. $1 \mathrm{H}$ & Gallagher distance & REV & Overall effect & Continuous variable & ANOVA repeated-measures $F$-test & $F=7.694$ & & & & $<0.001$ \\
\hline Fig. $1 \mathrm{H}$ & Gallagher distance & REV & TS_WT & Continuous variable & ANOVA repeated-measures $F$-test & 2114.3 & 412 & 1306.78 & 2921.82 & $<0.001$ \\
\hline Fig. $1 \mathrm{H}$ & Gallagher distance & REV & TS EE-EGCG_TS & Continuous variable & ANOVA repeated-measures $F$-test & -869 & 443.3 & -1737.87 & -0.132 & 0.059 \\
\hline Not shown & Gallagher index & REV & Overall effect & Continuous variable & ANOVA repeated-measures $F$-test & $F=11.714$ & & & & $<0.001$ \\
\hline Not shown & Gallagher index & REV & TS_WT & Continuous variable & ANOVA repeated-measures $F$-test & 20.8045 & 4.3102 & 12.35651 & 29.25249 & $<0.001$ \\
\hline Not shown & Gallagher index & REV & TS EE-EGCG_TS & Continuous variable & ANOVA repeated-measures $F$-test & -6.3488 & 4.638 & -15.4393 & 2.74168 & 0.2 \\
\hline Fig. $1 \mathrm{H}$ & Thigmotaxis & REV & Overall effect & Continuous variable & ANOVA repeated-measures $F$-test & $F=10.105$ & & & & $<0.001$ \\
\hline Fig. $1 \mathrm{H}$ & Thigmotaxis & REV & TS_WT & Continuous variable & ANOVA repeated-measures $F$-test & 21.393 & 6.268 & 9.10772 & 33.67828 & 0.001 \\
\hline Fig. $1 \mathrm{H}$ & Thigmotaxis & REV & TS EE-EGCG_TS & Continuous variable & ANOVA repeated-measures $F$-test & -9.867 & 6.745 & -23.0872 & 3.3532 & 0.14 \\
\hline Not shown & Speed & REV & Overall effect & Continuous variable & ANOVA repeated-measures $F$-test & $F=2.607$ & & & & 0.067 \\
\hline
\end{tabular}

respectively. Statistical significance was set at 0.05 . The significance levels for the three contrasts of interest were adjusted to guarantee a family-wise error rate of 0.05 .

\section{Results}

\section{Effects of EE-EGCG treatment on}

corticohippocampal-dependent learning and memory impairment in Ts65Dn mice

To evaluate the effect of EE-EGCG treatment, we compared the behavioral performance of WT and Ts65Dn mice treated with EE-EGCG with their untreated counterparts in the MWM. During the acquisition sessions, there were statistical differences among all groups in escape latency, distance to the target [as shown by both the Gallagher index (mean distance to the platform) and the Gallagher (accumulated) distance to the platform], and thigmotactic behavior, (percentage of time spent close to the periphery) the percentage of time spent close to the periphery of the pool (Table 1).

We detected learning defects in Ts65Dn mice compared with WT (Fig. 1A) as shown by the higher escape latency across sessions (Fig. 1B; Table 1), increased Gallagher distance and index (Fig. 1A, C; Table 1), and typical increase in thigmotactic behavior (Fig. 1A, D; Table 1).

EE-EGCG-treated Ts65Dn mice showed improved learning performance during the acquisition sessions (Fig.
1A). In comparison to untreated Ts65Dn mice, EE-EGCGtreated TS mice presented significantly reduced escape latency (Fig. 1B; Table 1) and Gallagher distance and index (Fig. 1A, $C$; Table 1) but no statistical differences in thigmotactic behavior (Fig. 1A, D; Table 1). Conversely, EE-EGCG-treated WT mice did not show differences compared with untreated WT mice.

There were differences in swimming speed among the groups; specifically, Ts65Dn mice had lower swimming speeds than WT mice (data not shown; Table 1). However, EE-EGCG did not promote significant changes in swimming speed in Ts65Dn or WT with respect to the untreated condition (data not shown; Table 1). This suggests that the learning differences in EE-EGCG-treated Ts65Dn mice are not mediated by changes in swimming speed.

To assess reference memory, a probe trial (removal session) was performed $24 \mathrm{~h}$ after the final acquisition day. In this session, there were no differences among groups in the percentage of time spent in the target quadrant, probably because of the high variability of the data (data not shown). However, the latency to the first entry to the platform area and the Gallagher distance, which is a more precise performance measure (Maei et al., 2009), showed significant differences among experimental groups (Fig. 1A, E, F; Table 1). Post hoc analysis demonstrated higher values of Ts65Dn mice in the Gal- 
A
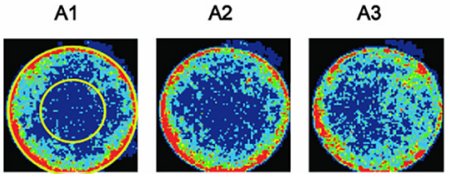

A4
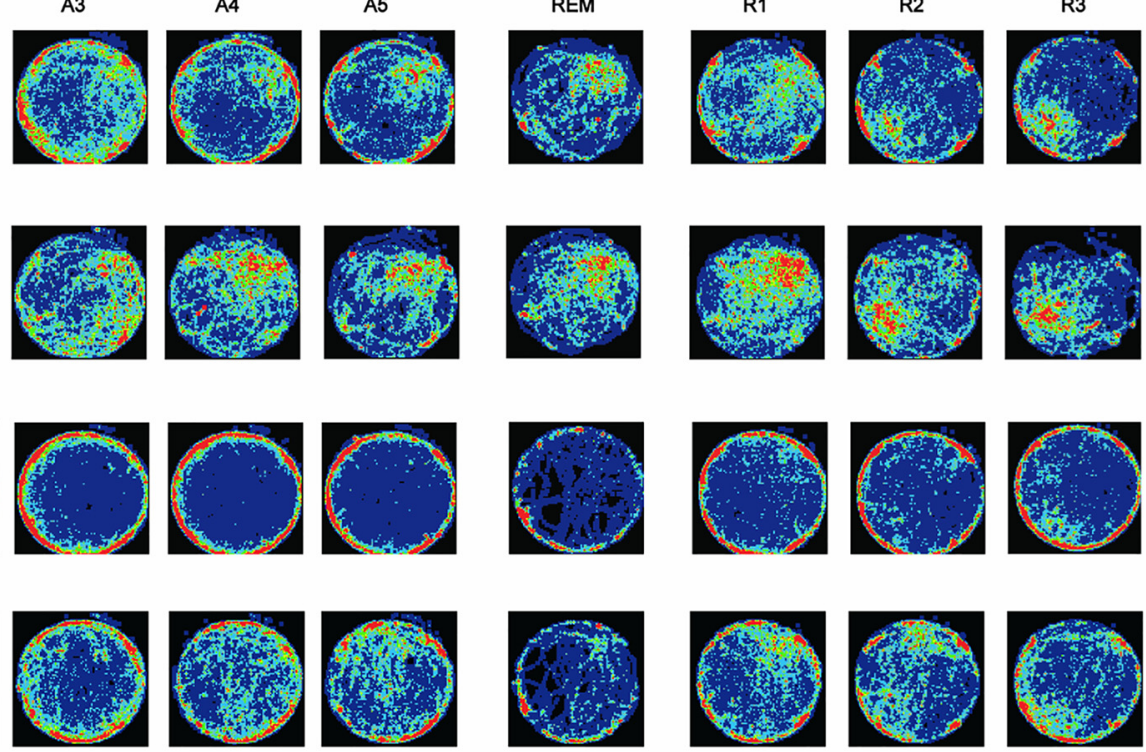

G

Cognitive flexibility (REVERSAL)
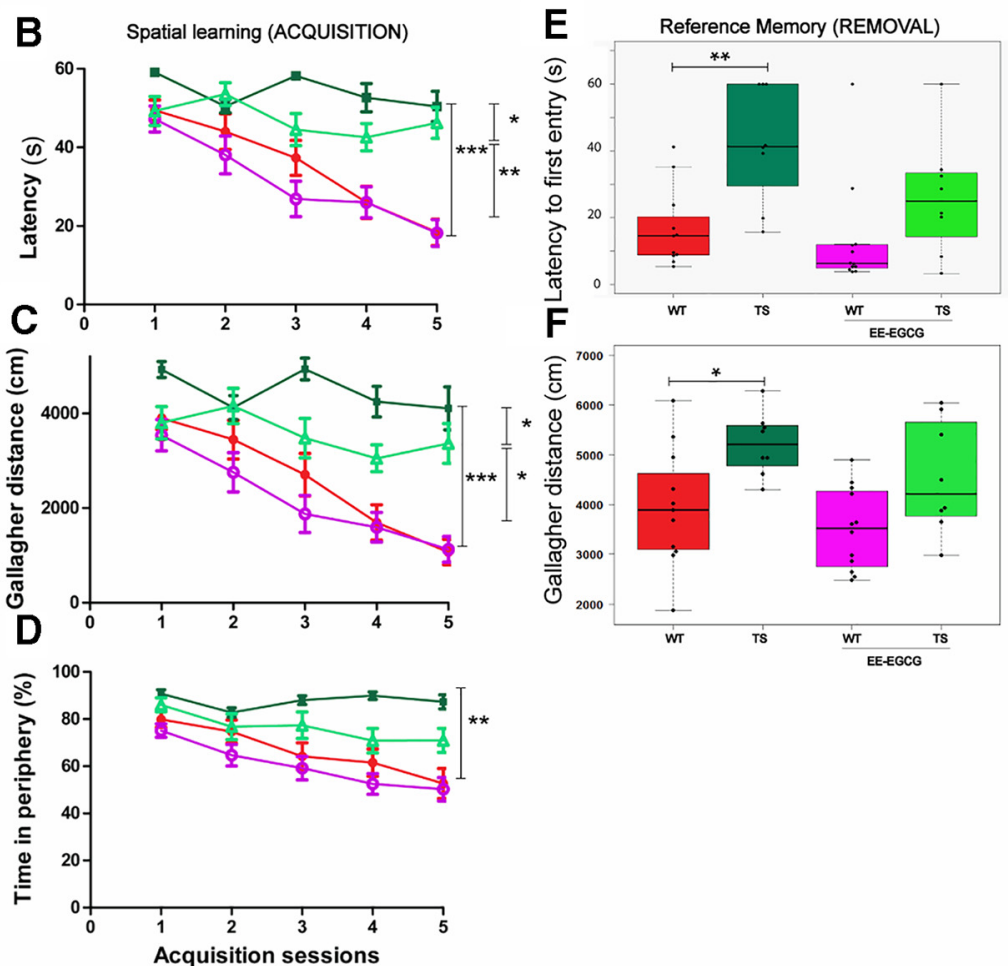
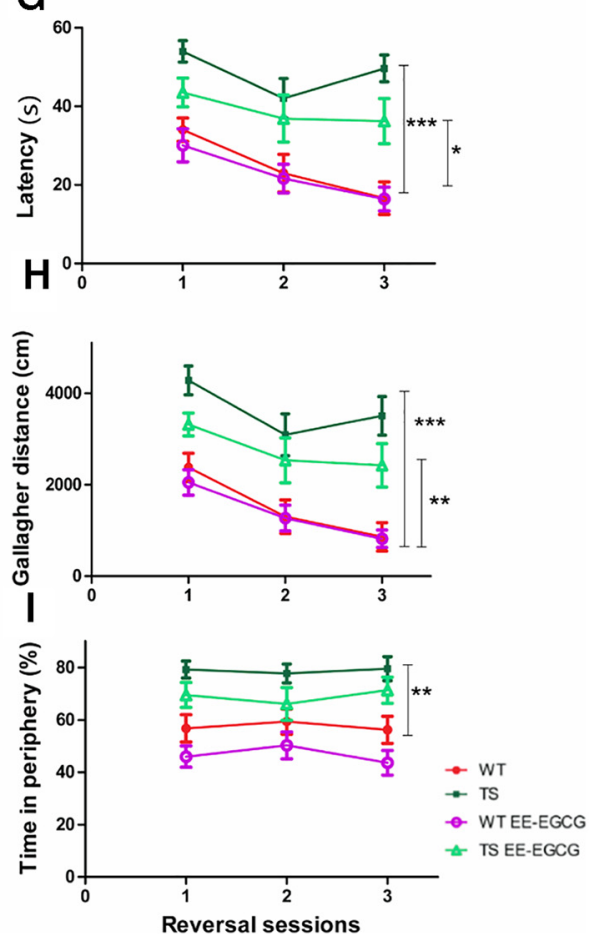

Figure 1. EE-EGCG treatment effects on young Ts65Dn mice deficits in spatial learning, reference memory and cognitive flexibility. $\boldsymbol{A}$, Heat map representing the accumulated swimming trajectories of mice from the different experimental groups across acquisition, removal, and reversal sessions in the MWM. Periphery and center zones are depicted at upper left. Color code is represented on the right, with red corresponding to the most visited zones and black to less visited or nonvisited zones. Learning curves are represented in latency (s) to reach the escape platform $(\boldsymbol{B})$, Gallagher distance (accumulated distance to the goal in $\mathrm{cm}$; $\boldsymbol{C}$ ), and thigmotaxis (percentage of time spent on the periphery; $\boldsymbol{D}$ ) during the acquisition sessions. $\boldsymbol{E}, \boldsymbol{F}$, Boxplots of the distribution of latency to the first entry to the platform area and the Gallagher distance of the four experimental groups in the removal session. Dots indicate the values of each individual mouse. Reversal learning curves are represented in latency (s; $\boldsymbol{G})$, Gallagher distance $(\boldsymbol{H})$, and thigmotaxis $(\boldsymbol{I})$. A1-5, acquisition sessions 1-5; R1-3, reversal sessions 1-3 with four trials per day; REM, removal session. Data in $\boldsymbol{B}, \boldsymbol{C}, \boldsymbol{D}, \boldsymbol{F}, \boldsymbol{G}$, and $\boldsymbol{H}$ are mean \pm SEM. Data in $\boldsymbol{B}$ and $\boldsymbol{F}$ were analyzed by a censored model, which considered $60 \mathrm{~s}$ as the maximum trial duration. Data in $\boldsymbol{C}, \boldsymbol{D}, \boldsymbol{G}$, and $\boldsymbol{H}$ were analyzed with ANOVA repeated measures, and data in $\boldsymbol{E}$ were analyzed by one-way ANOVA. In all cases, Tukey multiple post hoc comparisons corrected with Benjamini-Hochberg were used. Even if all groups were considered for multiple comparisons, the figure reports only statistically significant differences of the following relevant contrasts of interest: WT versus TS; TS versus TS EE-EGCG; WT versus TS EE-EGCG. $* p<0.05, * * p<0.01, * * * p<0.001$ 
lagher distance and the latency to the first entry compared with WT mice (Fig. 1A, E, F; Table 1), indicating poorer reference memory. The mean difference in these parameters between EE-EGCG-treated and untreated Ts65Dn mice was fairly large; however, it did not reach statistical significance, possibly because of high variability of the data (Fig. 1A, E, F; Table 1).

In the reversal sessions, we detected statistical differences among the experimental groups in escape latency, Gallagher distance and index, and thigmotaxis (Table 1). Whereas untreated WT mice efficiently shifted their search to the new platform position (Fig. 1A), Ts65Dn mice had increased escape latency (Fig. 1G; Table 1), increased Gallagher distance and index (Fig. 1A, $\mathrm{H}$; Table 1), and increased thigmotaxis across the three reversal learning sessions (Fig. 1A, l; Table 1), compared with WT mice. During reversal, there was no significant reduction in thigmotaxis, suggesting that this variable was not associated with reversal learning.

EE-EGCG-treated Ts65Dn mice showed a fairly large (although not statistically significant) reduction in the latency to reach the new platform position compared with untreated Ts65Dn mice (Fig. 1A, G; Table 1). There were no significant differences between EE-EGCG-treated and untreated Ts65Dn mice in Gallagher distance or index (Fig. $1 A, H$; Table 1) or thigmotaxis (Fig. 1A, l; Table 1). EE-EGCG-treated and untreated WT mice showed no significant differences in the latency to reach the new platform position, the Gallagher distance or index, or thigmotaxis. During the reversal sessions, there were no statistical differences in swimming speed among the experimental groups (not shown; Table 1).

\section{Multidimensional analysis of learning using PCA}

PCA enabled placement of the experimental groups in a low-dimensional coordinate system built from variables taken during the MWM experiment. A group's progression along the acquisition sessions became apparent in its resulting 5-day trajectory (Fig. $2 A$ ). We obtained a PC1 that explained $84 \%$ of the between-group variance and was mainly composed of learning-related variables (i.e., escape latency, Gallagher index, percentage of time spent in periphery, Whishaw index, distance traveled, percentage of time spent in target quadrant; Figs. 2B, C). Swimming speed also contributed to PC1, but to a lesser extent. Efficient learning behaviors (short distances to target, low escape latencies, high percentages of time in the target quadrant, etc.) correspond to large values of PC1 (Fig. 2B), and thus PC1 can be interpreted as a quantification of learning. In contrast, PC2 explained $11 \%$ of between-group variance and was mainly composed of swimming speed (Figs. 2B, D). This component of speed is unrelated to learning, since PC2 is orthogonal to the learning-related PC1. It thus seems to reflect motor performance rather than determination to reach the target quickly. Swimming speed is thus decomposed in a learning-dependent component (PC1) and a learningindependent component (PC2). Learning-related variables contributed to a much lesser extent to PC2.
Because a group trajectory represents a group's overall learning through its progression along PC1, the trajectory representation allows for effective comparisons between group performances. Untreated Ts65Dn mice showed a trajectory reaching a maximum value of $\mathrm{PC} 1$ that corresponds to initial PC1 values of the untreated WT trajectory, revealing poor learning. On the other hand, the EEEGCG-treated Ts65Dn trajectory attained more advanced maximum values of PC1.

Additionally, we determined individual variation within the groups by mapping the position of each individual on each acquisition day on the PCA plot. As shown in the density plots of sessions 1 and 5 in Fig. $2 E$, there is substantial individual variation across learning sessions in all the experimental groups. In fact, overall group differences explain less than half of the total variance. Withingroup variance, however, differs between experimental groups. Whereas WT mice generally show higher variability than Ts65Dn mice, the treatment roughly doubles variance for both genotypes in the first learning session. Interestingly, learning increases variability in all groups. This effect is stronger for untreated groups, so treated and untreated groups show similar variability in the final learning session. We summarize within-group variances of the first and last acquisition sessions in Table 2.

To assess the statistical significance of differences in learning, we performed a permutation test involving a $t$ statistic based on PC1. Untreated Ts65Dn mice had significantly lower PC1 values in comparison to WT mice in the first learning session (Fig. 2F; Table 3). EE-EGCGtreated Ts65Dn mice had higher PC1 than untreated Ts65Dn mice (Fig. 2F; Table 3); at this stage, the difference could be associated with procedural learning and was not significantly different from untreated WT (Fig. 2F; Table 3). At the end of the learning period (session 5), untreated Ts65Dn mice still had significantly lower PC1 values in comparison to WT mice (Fig. 2F; Table 3). EEEGCG-treated Ts65Dn mice exhibited higher PC1 than untreated Ts65Dn mice, although they showed significantly lower PC1 values than untreated WT mice (Fig. 2F; Table 3). On the other hand, EE-EGCG treatment did not significantly change learning outcomes of WT mice in either the first or the last session.

Similarly, group trajectories comprising three time points each were obtained for the reversal sessions (Fig. $3 A$ ). Here, PC1 explained $84 \%$ of the between-group variance and, as in the acquisition sessions, was dominated by learning-related variables (Fig. 3B, C). PC2, which explained $12 \%$ of the between-group variance, showed again a strong contribution of swimming speed. The main contribution here, however, turned out to be from thigmotaxis (Fig. 3B, D). Interestingly, these two variables fall on a line separating the groups along an efficiency gradient from strong thigmotaxis and low speed to no thigmotaxis and high speed in the order TS, TS-EEEGCG, WT, and WT-EE-EGCG (Fig. 3A, B). Again, there was an increased within-group variability associated with the learning process in all groups (Fig. 3E; Table 2).

According to the permutation tests, untreated Ts65Dn mice showed significantly lower PC1 than untreated WT 
A

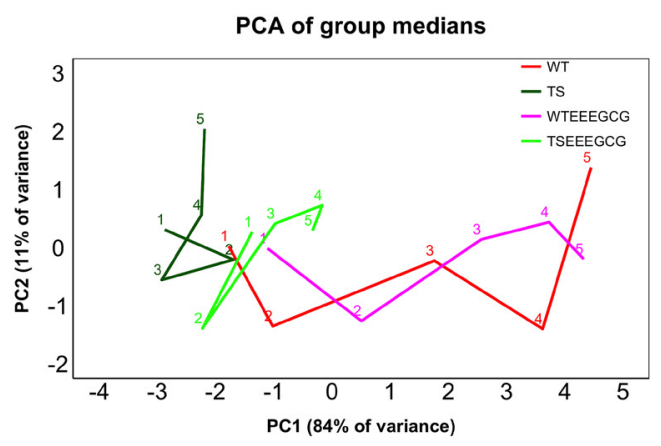

C

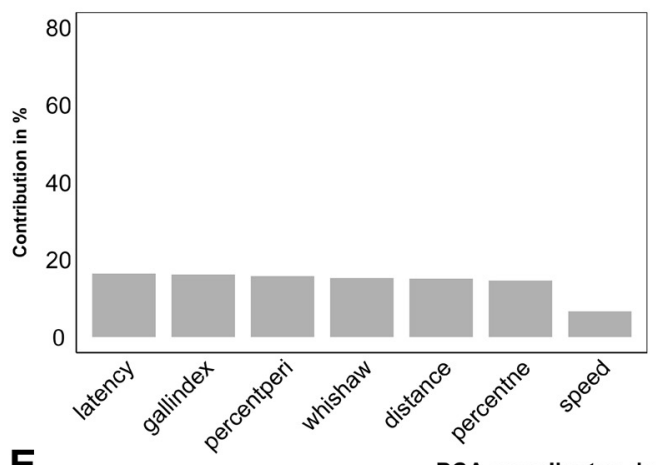

B

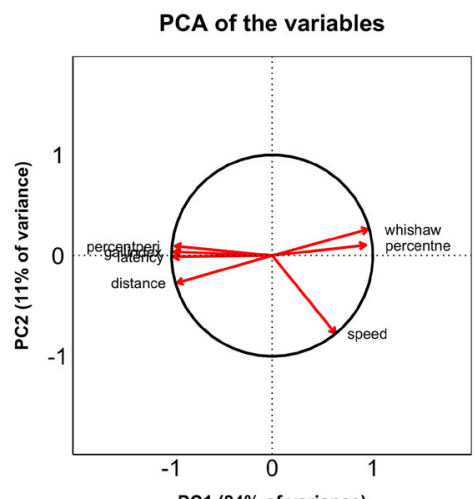

D

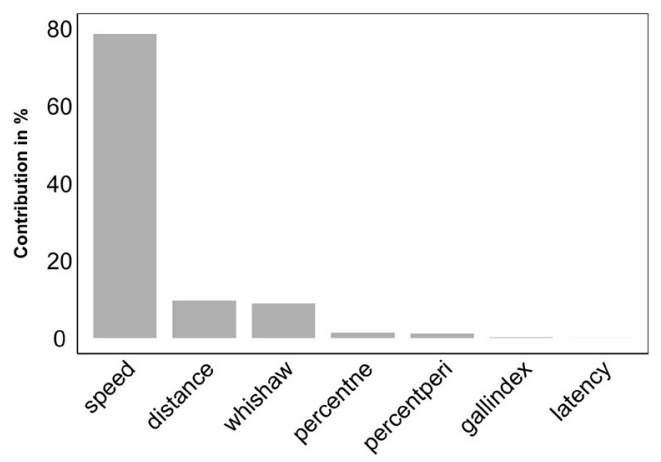

E

PCA coordinates density, session 1 and 5

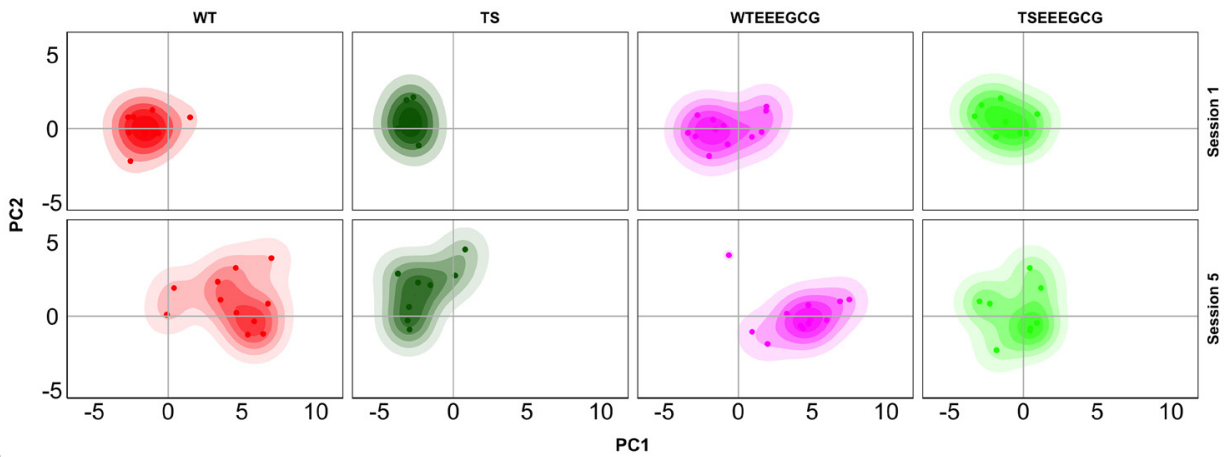

F

PC1 distribution

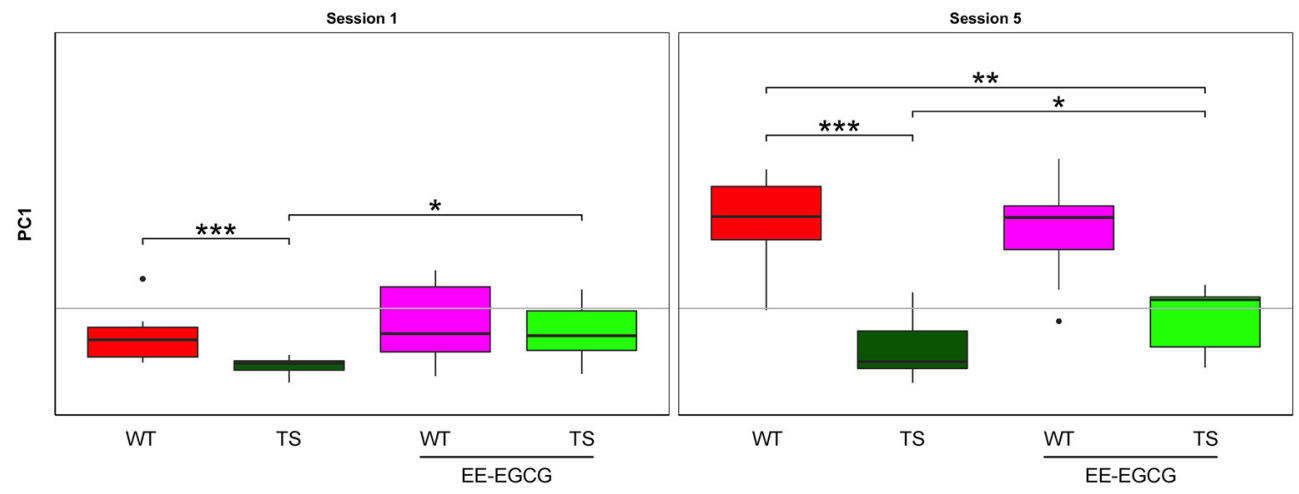

Figure 2. Supervised PCA of the experimental groups during the acquisition sessions revealed that EE-EGCG treatment improves global learning in Ts65Dn mice. A, Trajectories connect group performance (medians) along the five learning sessions (labeled with respective numbers) in the space defined by PC1 and PC2, which consist of linear combinations of the original variables. $\boldsymbol{B}$, Variable directionality in the PCA space. Arrows represent the direction with respect to PC1 and PC2. Variables reaching the unit circle belong to variables that are well represented by the two principal components. Contribution of variables to PC1 (C) and PC2 (D) in percent. $\mathrm{PC} 1$ receives a similar contribution from all classic variables used to assess learning and can thus be understood as a composite 
continued

learning variable. $\boldsymbol{E}$, Boxplots of PC1 distribution for each experimental group on sessions 1 and 5 of the acquisition phase. Box plot horizontal lines, group median; box edges, 25th and 75th percentiles; whiskers, minimum and maximum values to a maximum of 1.5 times the interquartile distance from the box. More extreme values are individually plotted. Only relevant comparisons are reported in the figure for the sake of clarity (WT versus TS; TS versus TS EE-EGCG; WT versus TS EE-EGCG), even if all groups were considered for the permutation test. $* p<0.05$, $* * p<0.01$, $* * * p<0.001$. The benefits of the EE-EGCG treatment on Ts65Dn learning explain the displacement of this group toward more positive values along the PC1.

mice (Fig. 3F; Table 2). EE-EGCG-treated Ts65Dn mice had significantly higher PC1 than untreated Ts65Dn mice, although they still showed significantly lower PC1 than WT mice (Fig. 3F; Table 2). In WT mice, EE-EGCG treatment did not modify cognitive flexibility outcomes in the first or the last session.

\section{Effects of EE-EGCG treatment on recognition deficits in Ts65Dn mice}

To assess the impact of the treatment on a less stressful learning task, we conducted a novel object recognition test. The performance of this test depends on the functionality of the entorhinal and perirhinal cortices and the hippocampus (Brown and Aggleton, 2001).

Table 2. Multivariate within-group variances (sum over squared distances from group barycenter divided by group size, scaled by number of variables) before and after acquisition, and reversal sessions.

\begin{tabular}{llllll}
\hline Figure & Session & WT & WT-EE-EGCG & TS & TS-EE-EGCG \\
\hline Fig. 2E & ACQ1 & 0.42 & 0.89 & 0.24 & 0.53 \\
Fig. 2E & ACQ5 & 1.62 & 1.55 & 0.87 & 0.95 \\
Fig. 3E & REV1 & 1.52 & 1.12 & 0.56 & 1.22 \\
Fig. 3E & REV3 & 2.68 & 1.84 & 1.42 & 2.26 \\
\hline
\end{tabular}

In this test, Ts65Dn mice showed no deficit in their DI in comparison to WT mice, although a slight tendency to impairment was detected ( $p=0.08$; Fig. 4; Table 4). EE-EGCG-treated Ts65Dn mice had an increase in their DI with respect to their untreated counterparts (Fig. 4; Table 4) and scored at similar levels to WT mice (Fig. 4; Table 4). Conversely, EE-EGCG-treated WT mice showed a poorer performance than untreated WT mice (Fig. 4; Table 4).

\section{Effects of EE-EGCG treatment on dendritic spine density in Ts65Dn hippocampus}

Ts65Dn mice showed a significant reduction of dendritic spine density in the CA1 (Fig. 5A; Table 5) and DG (Fig. 5B; Table 5) hippocampal subregions. EE-EGCGtreated Ts65Dn mice did not show statistically significant differences in DG dendritic spine density compared with untreated Ts65Dn or WT mice (Fig. 5B). Conversely, EEEGCG-treated Ts65Dn mice had increased dendritic spine density in CA1 in comparison to untreated Ts65Dn mice (Fig. 5A; Table 5), and EE-EGCG-treated WT mice showed reduced CA1 dendritic spine density in comparison to untreated WT mice (Fig. 5A; Table 5).

Table 3. Permutation-test results of learning-related composite measure PC1.

\begin{tabular}{|c|c|c|c|c|c|}
\hline Figure & Variable & Phase & Contrast & Pseudo-t & $\overline{p \text {-value }}$ \\
\hline Fig. 2E & $\mathrm{PC} 1$ & ACQ1 & TS_WT & 3.67 & $<0.001$ \\
\hline Fig. $2 \mathrm{E}$ & PC1 & ACQ1 & TS_WT EE-EGCG & 3.57 & $<0.001$ \\
\hline Fig. 2E & PC1 & ACQ1 & TS_TS EE-EGCG & 3.05 & 0.004 \\
\hline Fig. 2E & PC1 & ACQ1 & TS EE-EGCG_WT & 0.28 & 0.39 \\
\hline Fig. 2E & PC1 & ACQ1 & TS EE-EGCG_WT EE-EGCG & 0.54 & 0.71 \\
\hline Fig. 2E & PC1 & ACQ1 & WT_WT EE-EGCG & 0.8 & 0.89 \\
\hline Fig. $2 \mathrm{E}$ & PC1 & ACQ5 & TS_WT & 6.81 & $<0.001$ \\
\hline Fig. 2E & PC1 & ACQ5 & TS_WT EE-EGCG & 6.72 & $<0.001$ \\
\hline Fig. 2E & PC1 & ACQ5 & TS_TS EE-EGCG & 1.85 & 0.045 \\
\hline Fig. $2 \mathrm{E}$ & PC1 & ACQ5 & TS EE-EGCG_WT & 5.2 & 9.99 \\
\hline Fig. $2 \mathrm{E}$ & PC1 & ACQ5 & TS EE-EGCG_WT EE-EGCG & 5.06 & $<0.001$ \\
\hline Fig. 2E & PC1 & ACQ5 & WT_WT EE-EGCG & 0.27 & 0.39 \\
\hline Fig. 3E & PC1 & REV1 & TS_WT & 4.60 & $<0.001$ \\
\hline Fig. 3E & $\mathrm{PC} 1$ & REV1 & TS_WT EE-EGCG & 5.60 & $<0.001$ \\
\hline Fig. 3E & PC1 & REV1 & TS_TS EE-EGCG & 2.59 & 0.01 \\
\hline Fig. 3E & PC1 & REV1 & TS EE-EGCG_WT & 2.44 & 0.01 \\
\hline Fig. 3E & $\mathrm{PC} 1$ & REV1 & TS EE-EGCG_WT EE-EGCG & 3.07 & 0.005 \\
\hline Fig. 3E & PC1 & REV1 & WT_WT EE-EGCG & 0.23 & 0.58 \\
\hline Fig. 3E & PC1 & REV3 & TS_WT & 5.17 & $<0.001$ \\
\hline Fig. $3 \mathrm{E}$ & PC1 & REV3 & TS_WT EE-EGCG & 6.19 & $<0.001$ \\
\hline Fig. 3E & PC1 & REV3 & TS_TS EE-EGCG & 2.32 & 0.02 \\
\hline Fig. 3E & PC1 & REV3 & TS EE-EGCG_WT & 2.66 & 0.01 \\
\hline Fig. 3E & PC1 & REV3 & TS EE-EGCG_WT EE-EGCG & 3.21 & 0.004 \\
\hline Fig. 3E & PC1 & REV3 & WT_WT EE-EGCG & 0.21 & 0.58 \\
\hline
\end{tabular}


A

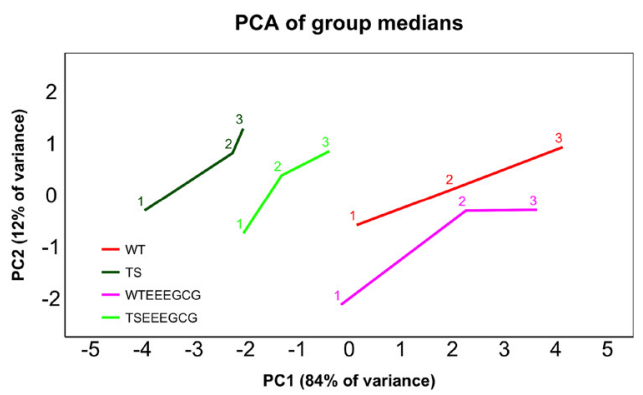

C

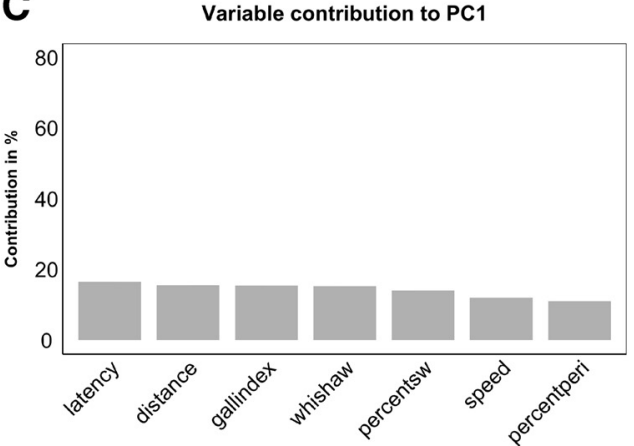

B

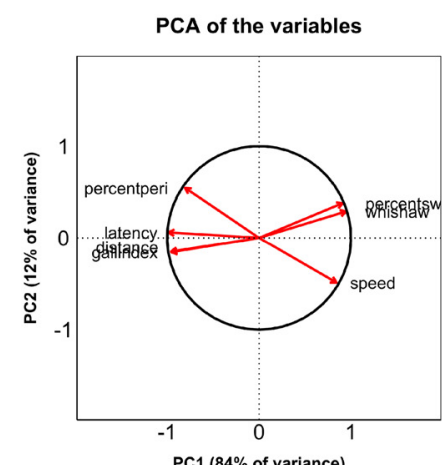

D

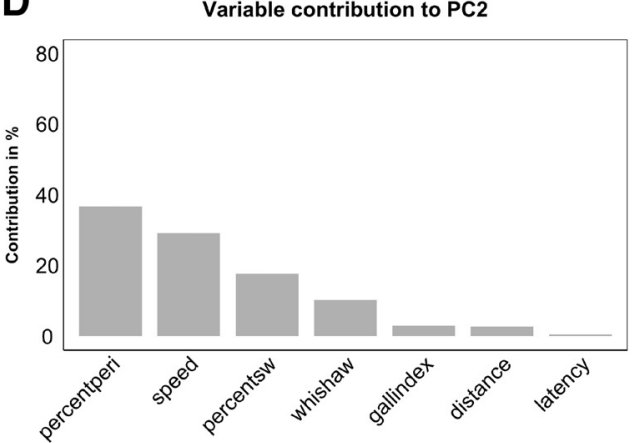

E

PCA coordinates density, reversal session 1 and 3

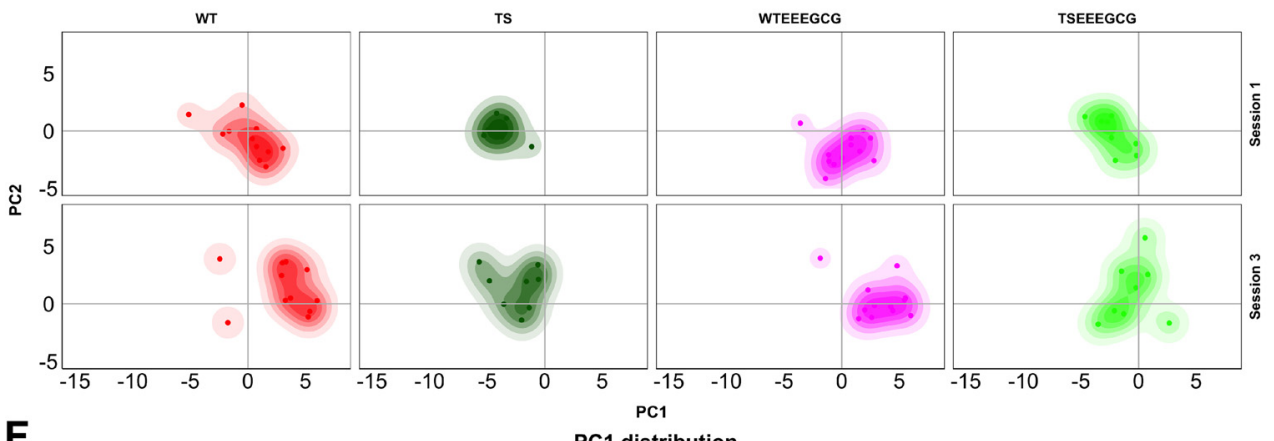

$\mathbf{F}$

PC1 distribution

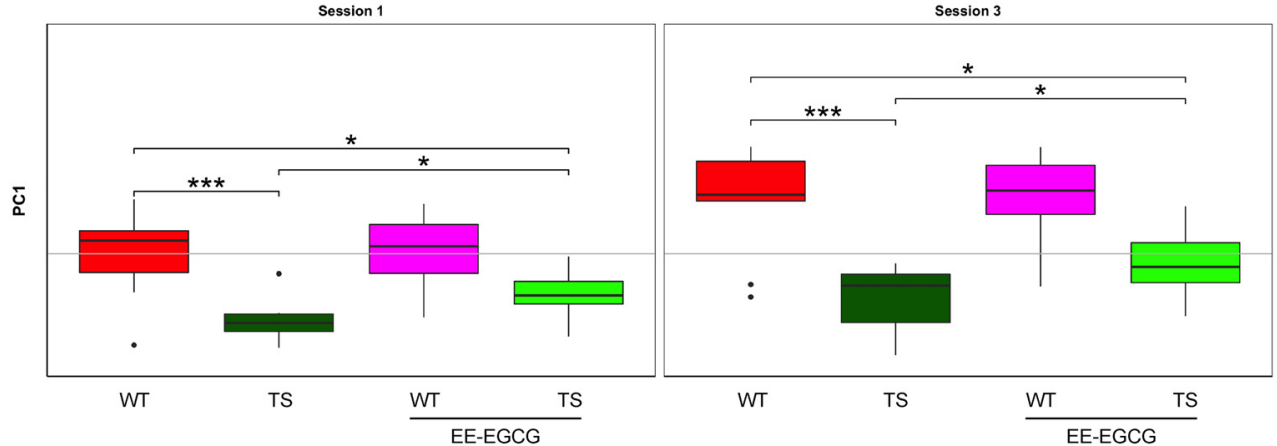

Figure 3. Supervised PCA of the experimental groups during the reversal sessions revealed poorer cognitive flexibility of untreated Ts65Dn mice. A, Trajectories of medians along the reversal session (accordingly labeled) on the space formed by PC1 and PC2. B, Variable directions on the PCA space defined by PC1 and PC2. Variables reaching the unit circle belong to variables that are well represented by the two principal components. Bar plots represent the contribution of variables to PC1 (C) and PC2 (D) in percent. $\boldsymbol{E}$, Box plots of PC1 distribution for each experimental group on sessions 1 and 3 of the reversal phase. Box plot horizontal lines, group median; box edges, 25th and 75th percentiles; whiskers, minimum and maximum values to a maximum of 1.5 times the interquartile distance from the box. More extreme values are individually plotted. Only relevant comparisons are reported in the figure for the sake of clarity (WT versus TS; TS versus TS EE-EGCG; WT versus TS EE-EGCG), even if all groups were considered for the permutation test. $* p<0.05, * * p<0.01, * * * p<0.001$. The shift of mouse groups toward positive values of PC1 represents the increased cognitive flexibility of the groups, with EE-EGCG-treated Ts65Dn mice attaining higher values than their untreated counterparts. 

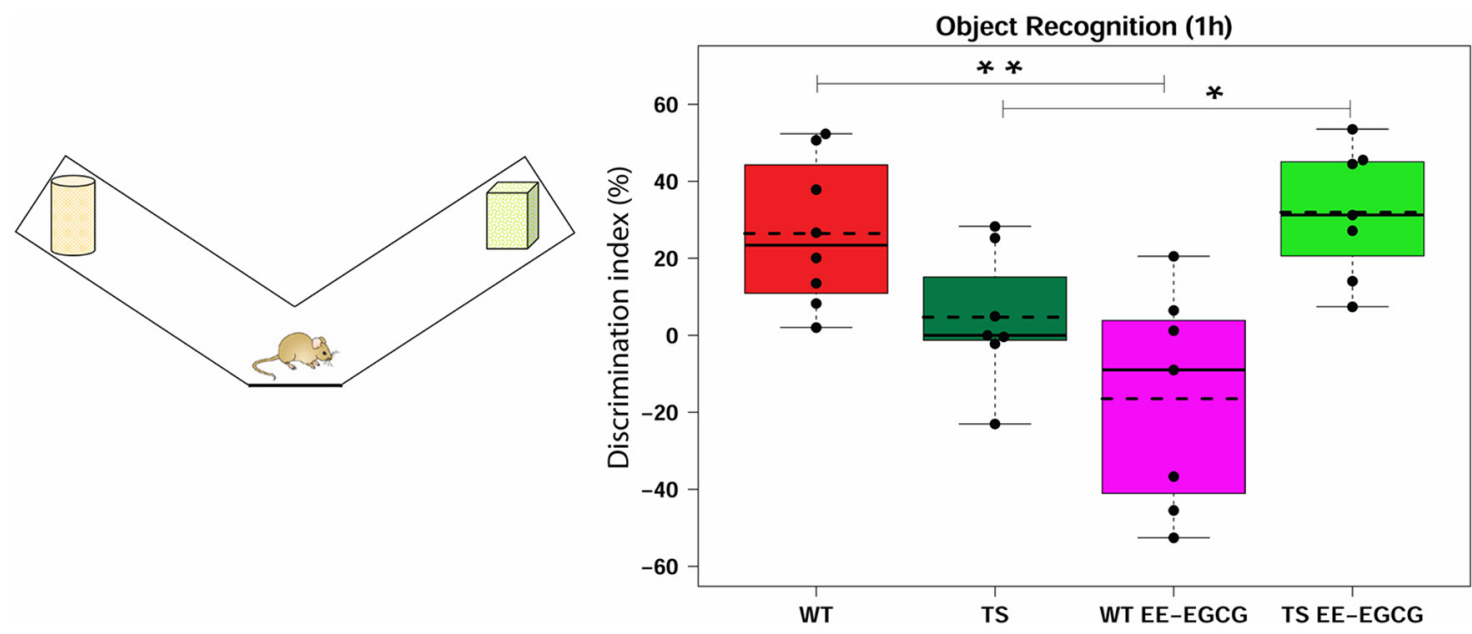

Figure 4. Effect of treatment on DI in the novel object recognition test. Left, diagram of the apparatus used for the novel object recognition test. Right, boxplots of the distribution of the DI (\%) among the experimental groups. Dots, DI measure from each individual mouse; dashed lines, group means; continuous lines, group medians. Data were analyzed using one-way ANOVA and Tukey multiple post hoc comparisons corrected with Benjamini-Hochberg. Even if all groups were considered for multiple comparisons, the figure reports only statistically significant differences of the following relevant contrasts of interest: WT versus TS; TS versus TS EE-EGCG; WT versus TS EE-EGCG. $* p<0.05, * * p<0.01$. Ts65Dn mice show a trend toward a reduction in DI $(p=0.08)$. EE-EGCG treatment improves DI score in Ts65Dn mice but worsens performance in WT mice.

\section{Effects of EE-EGCG treatment on hippocampal excitatory and inhibitory synaptic puncta in Ts65Dn mice}

In DG, Ts65Dn mice showed increased VGLUT1 puncta density (data not shown; Table 6) of reduced size (data not shown; Table 6), and no differences in the number or size of VGAT puncta compared with WT mice. This resulted in an increased VGLUT1/NGAT density ratio (Fig. 6A; Table 6). Because the increase in the number of VGLUT1 puncta was compensated by a reduction in size, Ts65Dn mice showed no difference in the VGLUT1NGAT percentage of area occupied compared with WT mice (Fig. 6B; Table 6).

In CA1, Ts65Dn mice also showed significantly increased density of VGLUT1 puncta of reduced size compared with WT mice (data not shown; Table 6). As in DG, Ts65Dn mice presented no differences in VGAT density puncta in CA1, but in this region, VGAT puncta were enlarged (data not shown; Table 6). This resulted in an increased ratio of VGLUT1/VGAT puncta density (Fig. 6C; Table 6), and a reduced VGLUT1/NGAT percentage of area occupied (Fig. 6D; Table 6).

Compared with untreated conditions, EE-EGCGtreated Ts65Dn mice exhibited a significant reduction in the density of VGLUT1 puncta in DG (data not shown;
Table 6) but not in CA1. VGLUT1 puncta were significantly enlarged in DG (data not shown; Table 6) but not in CA1. There were no significant differences in VGAT puncta number or size between EE-EGCG-treated and untreated Ts65Dn mice in DG or CA1. As a result, EE-EGCG-treated Ts65Dn mice showed a reduction in the ratio of VGLUT1/ VGAT density in both DG (Fig. 6A; Table 6) and CA1 (Fig. $6 C$; Table 6), leading to values that were similar to those of WT mice. On the other hand, EE-EGCG-treated WT mice also showed a trend toward an enlargement of VGAT puncta size in CA1 (data not shown; Table 6), leading to a decreased VGLUT1/VGAT percentage of area occupied (Fig. 6D; Table 6) in comparison to untreated WT mice.

\section{Discussion}

In the present study, combined EE-EGCG treatment significantly increased spine density in CA1, normalized excitatory and inhibitory synaptic markers in CA1 and DG, and improved performance in a corticohippocampaldependent learning task in young Ts65Dn mice.

In line with previous studies, we detected poor learning strategies and hippocampal-dependent learning and memory performance in the MWM in young Ts65Dn mice (Escorihuela et al., 1995; Reeves et al., 1995). In Ts65Dn

Table 4. Novel object recognition test (discrimination index).

\begin{tabular}{|c|c|c|c|c|c|c|c|}
\hline \multirow[b]{2}{*}{ Figure } & \multirow[b]{2}{*}{ Contrast } & \multirow[b]{2}{*}{ Data structure } & \multirow[b]{2}{*}{ Type of test } & \multirow{2}{*}{$\begin{array}{l}\text { Estimated mean } \\
\text { difference }\end{array}$} & \multicolumn{2}{|c|}{$\begin{array}{l}95 \% \text { confidence } \\
\text { interval }\end{array}$} & \multirow[b]{2}{*}{$p$-value } \\
\hline & & & & & Lower & Higher & \\
\hline Fig. 4 & TS_WT & Continuous variable & ANOVA & -21.728 & -42.94 & -0.511 & 0.083 \\
\hline Fig. 4 & TS EE-EGCG_TS & Continuous variable & ANOVA & 27.224 & 5.311 & 49.136 & 0.044 \\
\hline Fig. 4 & TS EE-EGCG_WT & Continuous variable & ANOVA & 5.496 & -15.721 & 26.713 & 0.616 \\
\hline
\end{tabular}




\section{Dendritic spine density}
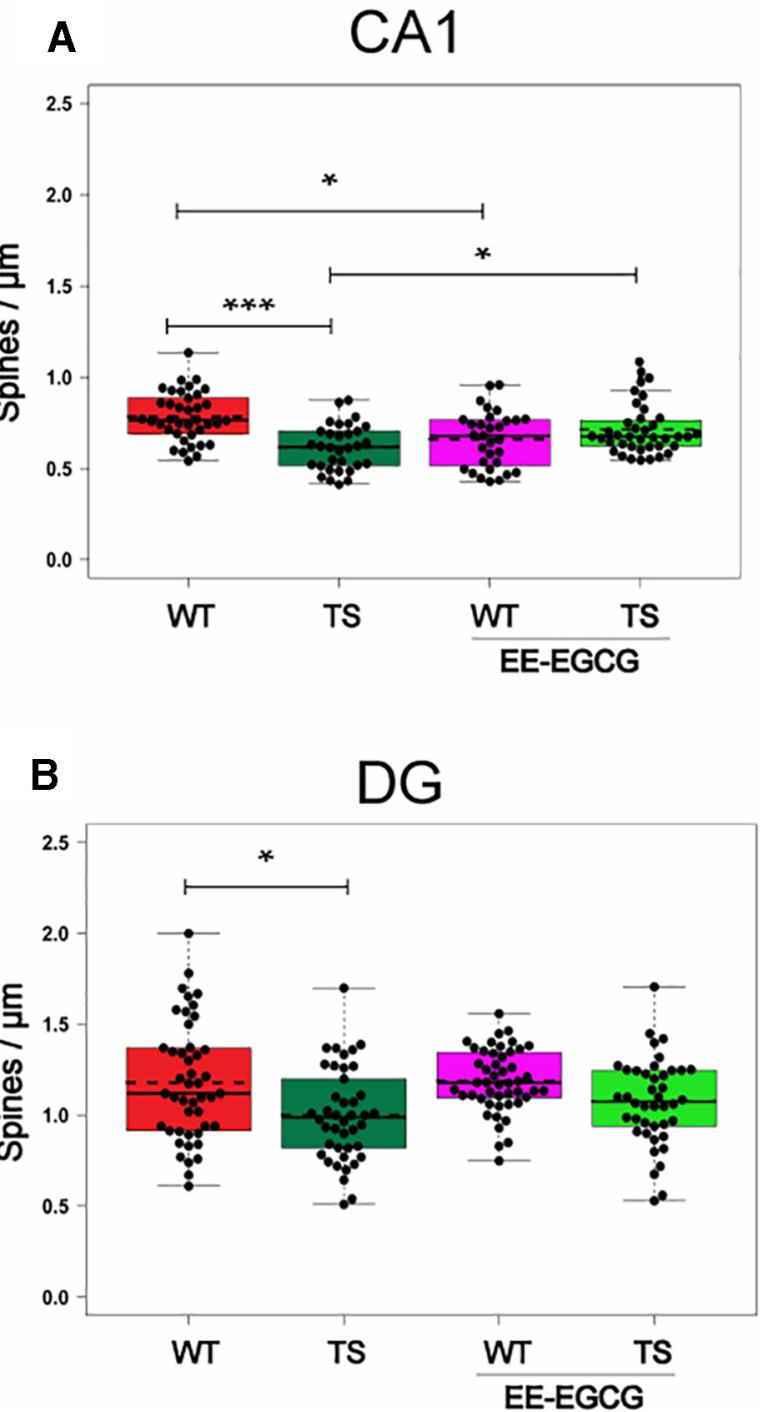

Figure 5. Ts65Dn mice show a reduction in dendritic spine density in DG and CA1, and EE-EGCG treatment ameliorates this deficit in CA1. Left, dorsal hippocampal region of a Golgi preparation illustrating dendrites from CA1 and DG subregions; scale bar represents $10 \mu \mathrm{m}$. $\boldsymbol{A}, \boldsymbol{B}$, Boxplots of the distribution of dendritic spine density (spines per micrometer) in DG and CA1 among the experimental groups. Dots, repeated values from individual mice (two to three dendrites per slice, three dorsal hippocampal slices per brain, five to six mice per experimental group); dashed lines, group means; continuous lines, group medians. Data were analyzed with a linear mixed model, which included experimental group as a factor and mouse as a random effect. $F$ test was used to test the global hypothesis. Post hoc tests were applied for the following contrasts of interest: WT versus TS; TS versus TS EE-EGCG; WT versus WT-EE-EGCG. $* p<0.05, * * * p<0.001$. Ts65Dn mice show a significant reduction in spine density in both DG and CA1. EE-EGCG treatment increases dendritic spine density in Ts65Dn CA1 and decreases this parameter in WT.

mice, but not WT mice, EE-EGCG treatment improved performance in the MWM, reducing escape latency and Gallagher index and distance during the learning sessions. PCA confirmed that untreated Ts65Dn showed inefficient learning progress over acquisition sessions, reaching maximum values of $\mathrm{PC1}$, a global learning variable, similar to initial WT values. EE-EGCG-treated Ts65Dn mice improved on global learning measures. They reached more advanced maximum $\mathrm{PC} 1$ values than untreated Ts65Dn mice, suggesting a modification in learning-related behavior as previously reported in middle-age Ts65Dn mice (Catuara-Solarz et al., 2015).

Ts65Dn mice also exhibited poor reference memory, as indicated by a significantly increased Gallagher index and distance and latency to the first entry to the platform area in the probe trial. However, no genotype effects were detected in other variables, such as time spent in the target quadrant or latency to first entry to target area, probably because of the high variability of the data. Additionally, Ts65Dn mice presented a deficit in cognitive 
Table 5. Dendritic spine density.

\begin{tabular}{|c|c|c|c|c|c|c|c|c|}
\hline \multirow[b]{2}{*}{ Figure } & \multirow[b]{2}{*}{ Region } & \multirow[b]{2}{*}{ Contrast } & \multirow[b]{2}{*}{ Data structure } & \multirow[b]{2}{*}{ Type of test } & \multirow{2}{*}{$\begin{array}{l}\text { Estimated mean } \\
\text { difference }\end{array}$} & \multicolumn{2}{|c|}{$\begin{array}{l}\text { 95\% confidence } \\
\text { interval }\end{array}$} & \multirow[b]{2}{*}{$p$-value } \\
\hline & & & & & & Lower & Higher & \\
\hline Fig. $5 \mathrm{~A}$ & DG & TS_WT & Continuous variable & Mixed-model $F$-test & -0.192 & -0.383 & -0.002 & 0.048 \\
\hline Fig. 5B & CA1 & TS_WT & Continuous variable & Mixed-model $F$-test & -0.175 & -0.282 & -0.069 & $<0.001$ \\
\hline Fig. 5B & CA1 & TS EE-EGCG_TS & Continuous variable & Mixed-model $F$-test & 0.105 & 0.001 & 0.209 & 0.047 \\
\hline Fig. 5B & CA1 & WT EE-EGCG_WT & Continuous variable & Mixed-model $F$-test & -0.129 & -0.234 & -0.025 & 0.01 \\
\hline
\end{tabular}

flexibility, as shown by the inefficient performance during the reversal sessions (executive function).

Single-variate analysis of different parameters between EE-EGCG-treated and untreated Ts65Dn mice did not reach statistical significance at reference memory and reversal sessions. However, a significant enhancement in cognitive flexibility was shown by multivariate analysis of the reversal sessions. In middle-age Ts65Dn mice, EEEGCG treatment improved learning and reference memory, but not cognitive flexibility (Catuara-Solarz et al., 2015). This suggests that EE-EGCG treatment effects depend on age and cognitive domain, possibly because of differential effects on different underlying brain regions and functions at different ages. EE-EGCG-treated WT mice did not show significant differences, possibly because of a ceiling effect.

MWM is a learning paradigm based on the stressful and aversive stimuli of the water pool, which triggers increases in plasma corticosterone, leading to a motivational state in the mice to learn the spatial configuration of the cues to escape (Harrison et al., 2009). Previous studies have shown that EGCG exerts an anxiolytic effect on different behavioral anxiety tests such as the forced swimming test, elevated plus maze, passive avoidance test, and tail suspension test (Dias et al., 2012). It could thus be speculated that the potential anxiolytic effects of EGCG would contribute to the learning improvement we found in the MWM. However, a number of facts suggest that the learning improvements found in treated Ts65Dn mice are not mainly contributed by the anxiolytic effect of EGCG. Ts65Dn mice have reduced levels of anxiety-like behavior in the elevated plus maze (Coussons-Read, 1996; Demas, 1996; Escorihuela, 1998; Shichiri, 2011), suggesting that the learning deficits shown by Ts65Dn in the MWM are not associated with anxiety. Thus a potential anxiolytic effect of EGCG would not eventually lead to significant learning improvement. Additionally, in the case of a potential MWM improvement associated with the anxiolytic effect of EGCG, we should be able to observe it in the control group that is subjected to the same anxiogenic scenario. However, in our study, the WT group did not benefit from the combined EE-EGCG treatment.

Even so, we also addressed the effects of the combined EE-EGCG treatment in a less stressful learning test, the novel object recognition test. The performance of this test depends on the functionality of the entorhinal and perirhinal cortices and the hippocampus (Brown and Aggleton, 2001; Brown et al., 2010). In this test, trisomic mice presented no significant deficit in their DI in comparison to WT mice, similar to some previous reports (Hyde and Crnic, 2002), although a slight tendency to impairment was detected that is in line with data from Fernandez et al. (2007). EE-EGCG-treated Ts65Dn mice presented an improvement in $\mathrm{DI}$ with respect to untreated counterparts and scored at similar levels to WT mice. On the other hand, EE-EGCG-treated WT mice showed a poorer performance than untreated WT mice, suggesting a possible deleterious effect of EGCG.

Table 6. VGLUT1 and VGAT synaptic puncta.

\begin{tabular}{|c|c|c|c|c|c|c|c|c|c|}
\hline \multirow[b]{2}{*}{ Figure } & \multirow[b]{2}{*}{ Variable } & \multirow[b]{2}{*}{ Region } & \multirow[b]{2}{*}{ Contrast } & \multirow[b]{2}{*}{ Data structure } & \multirow[b]{2}{*}{ Type of test } & \multirow{2}{*}{$\begin{array}{l}\text { Estimated mean } \\
\text { difference }\end{array}$} & \multicolumn{2}{|c|}{$\begin{array}{l}95 \% \text { confidence } \\
\text { interval }\end{array}$} & \multirow[b]{2}{*}{$p$-value } \\
\hline & & & & & & & Lower & Higher & \\
\hline Not shown & VGLUT1 puncta density & DG & TS_WT & Continuous variable & Mixed-model F-test & 0.077 & 0.018 & 0.136 & 0.006 \\
\hline Not shown & VGLUT1 puncta size & DG & TS_WT & Continuous variable & Mixed-model $F$-test & -0.06 & -0.098 & -0.022 & 0.001 \\
\hline Fig. $6 \mathrm{~A}$ & VGLUT1/NGAT puncta density & DG & TS _WT & Continuous variable & Mixed-model F-test & 0.308 & 0.151 & 0.465 & $<0.001$ \\
\hline Fig. $6 \mathrm{~B}$ & VGLUT1/NGAT $\%$ of area & DG & TS _WT & Continuous variable & Mixed-model F-test & 0.077 & -0.03 & 0.183 & 0.222 \\
\hline Not shown & VGLUT1puncta density & DG & TS EE-EGCG_TS & Continuous variable & Mixed-model $F$-test & -0.073 & -0.132 & -0.014 & 0.01 \\
\hline Not shown & VGLUT1 puncta size & DG & TS EE-EGCG_TS & Continuous variable & Mixed-model $F$-test & 0.06 & 0.022 & 0.098 & 0.001 \\
\hline Fig. $6 \mathrm{~A}$ & VGLUT1/NGAT puncta density & DG & TS EE-EGCG_TS & Continuous variable & Mixed-model $F$-test & -0.294 & -0.452 & -0.137 & $<0.001$ \\
\hline Not shown & VGLUT1 puncta density & CA1 & TS_WT & Continuous variable & Mixed-model F-test & 0.071 & 0.008 & 0.134 & 0.022 \\
\hline Not shown & VGLUT1 puncta size & CA1 & TS_WT & Continuous variable & Mixed-model $F$-test & -0.093 & -0.145 & -0.041 & 0.043 \\
\hline Not shown & VGAT puncta size & CA1 & TS _WT & Continuous variable & Mixed-model $F$-test & 0.054 & 0.001 & 0.106 & 0.043 \\
\hline Fig. $6 \mathrm{C}$ & VGLUT1/NGAT puncta density & CA1 & TS_WT & Continuous variable & Mixed-model $F$-test & 0.295 & 0.098 & 0.493 & 0.001 \\
\hline Fig. 6D & VGLUT1NGAT $\%$ of area & CA1 & TS_WT & Continuous variable & Mixed-model F-test & -0.145 & -0.275 & -0.016 & 0.023 \\
\hline Fig. $6 \mathrm{C}$ & VGLUT1/NGAT puncta density & CA1 & TS EE-EGCG_TS & Continuous variable & Mixed-model $F$-test & -0.245 & -0.442 & -0.047 & 0.01 \\
\hline Not shown & VGAT puncta size & CA1 & WT EE-EGCG_WT & Continuous variable & Mixed-model F-test & 0.049 & -0.003 & 0.102 & 0.07 \\
\hline Fig. 6D & VGLUT1/NGAT \% of area & CA1 & WT EE-EGCG_WT & Continuous variable & Mixed-model $F$-test & -0.137 & -0.267 & -0.007 & 0.035 \\
\hline
\end{tabular}


A

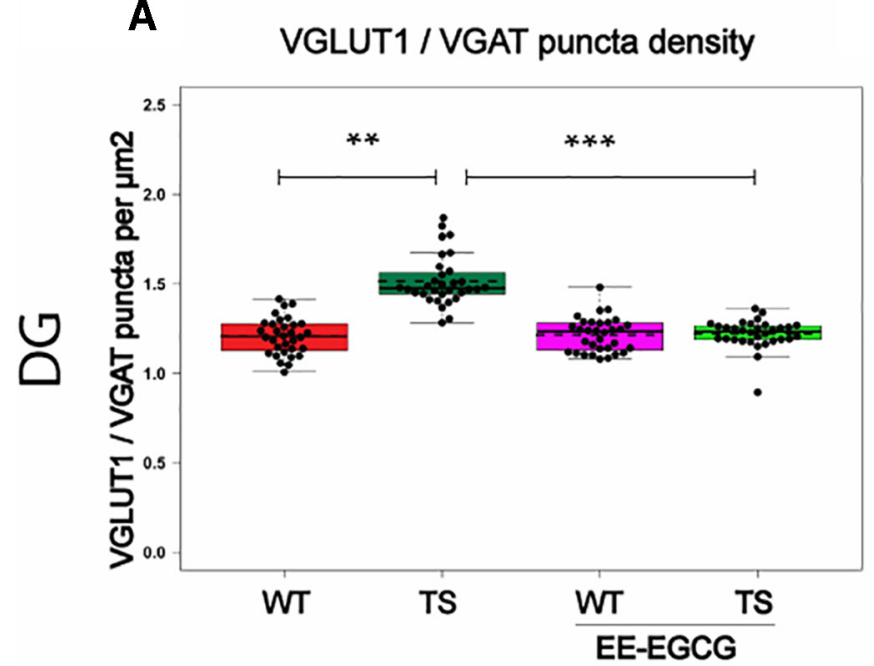

C

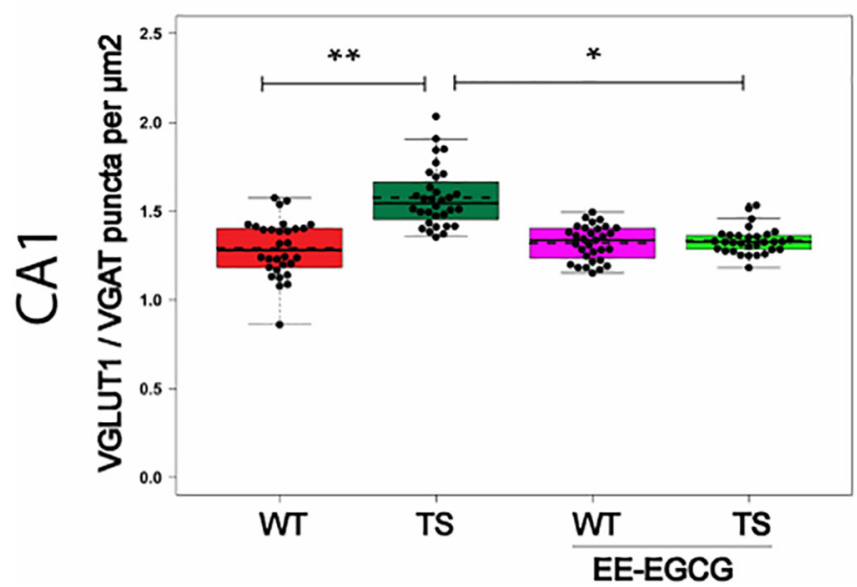

B

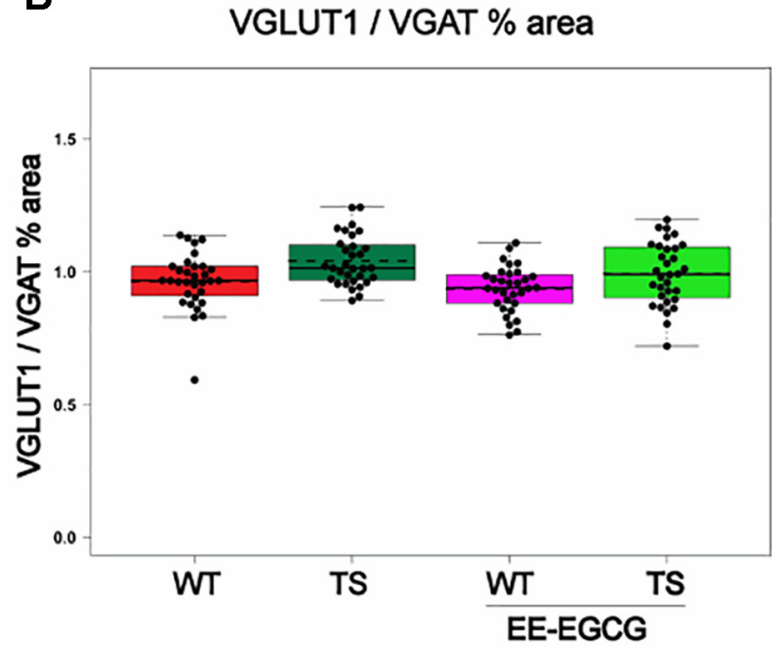

D

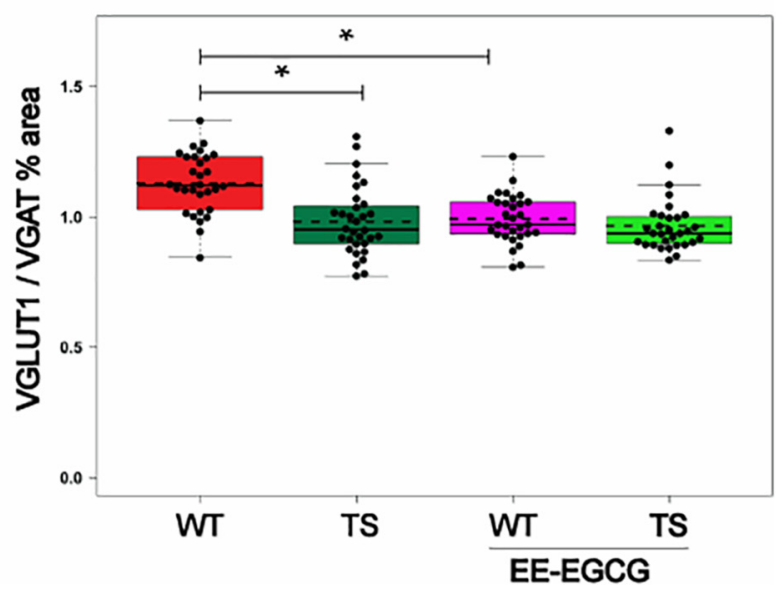

Figure 6. EE-EGCG effects on VGLUT1/VGAT puncta in DG and CA1. Box plots of the distribution of VGLUT1/VGAT ratios of different puncta density and percentage of area among the experimental groups at DG and CA1. $\boldsymbol{A}, \boldsymbol{C}$, VGLUT1/VGAT ratio of puncta density (puncta per square micrometer). $\boldsymbol{B}, \boldsymbol{D}$, VGLUT1/VGAT ratio of percentage of area occupied. Dots, repeated values from individual mice; dashed lines, group means; continuous lines, group medians. Data were analyzed with a linear mixed model, which included experimental group as a factor and mouse as a random effect. $F$ test was used to test the global hypothesis. Post hoc tests were applied for the following contrasts of interest: WT versus TS; TS versus TS EE-EGCG; WT versus WT-EE-EGCG. $* p<0.05, * * p<$ $0.01, * * * p<0.001$

Along with learning improvement, EE-EGCG-treated mice showed significant neuromorphologic changes in the hippocampus. Consistent with previous reports in DS (Ferrer and Gullotta, 1990) and Ts65Dn mice (Belichenko et al., 2004), we observed a reduction in dendritic spine density in outer molecular layer dendrites from granule cells of the DG, and in apical dendrites of pyramidal neurons of CA1 in Ts65Dn mice. Combined treatment with EE-EGCG partially rescued the dendritic spine density deficit in CA1, but not in the DG of Ts65Dn mice. A reduction of Dyrk1A kinase activity (Bain et al., 2003; Golabek et al., 2011; Pons-Espinal et al., 2013), but also other signaling pathways that are modified by both $\mathrm{EE}$ and EGCG, such as increased CREB and Akt phosphorylation (Jia et al., 2013; Ramírez-Rodríguez et al., 2014;
Ortiz-López et al., 2016) or increases in BDNF expression (Young et al., 1999; Li et al., 2009a, 2009b), could contribute to these neuroplasticity changes.

We also explored the effects of EE-EGCG treatment on E/I balance, using excitatory (VGLUT1) and inhibitory (VGAT) synaptic vesicle markers. In Ts65Dn DG, VGLUT1 puncta were more abundant but smaller, with no changes in the percentage of area occupied, whereas VGAT puncta showed no differences compared with WT littermates. In CA1, Ts65Dn mice showed the same phenotype, VGLUT1 puncta being more abundant and smaller; however, in this region, VGAT puncta were enlarged, leading to an increased VGLUT1/NGAT ratio but a reduction of VGLUT1/VGAT percentage of area occupied. That in both DG and CA1 VGLUT1 puncta were more abundant 
and smaller in Ts65Dn could affect the probability or efficiency in neurotransmitter release (Harris and Sultan, 1995; Bozdagi et al., 2000; Antonova et al., 2001; Bamji et al., 2006; Bourne et al., 2013) and could also be related to the previously reported enhanced $\mathrm{GABA}_{\mathrm{A}}$ and $\mathrm{GABA}_{\mathrm{B}}$ evoked inhibitory postsynaptic currents in DG of 3- to 4-month-old male mice (Kleschevnikov et al., 2012) and increased GABA release in the hippocampus of male and female adult mice (Begenisic et al., 2011). Consistent with our results, previous work showed no changes in density of VGAT puncta nor density of inhibitory synapses using electron microscopy in the DG of 3-month-old male mice, although apposition length of symmetric (inhibitory) synapses was larger (Belichenko et al., 2009). Additionally, Kleschevnikov et al. (2012) found no differences in GAD67 optical density in DG, with only a trend toward reduction in GAD67 in the outer molecular layer of 3- to 4-month-old male mice. A recent study using Western blot showed a reduction in the hippocampal expression of VGLUT1 and no statistical difference in VGAT (Souchet et al., 2015). Conversely, others have shown an increase in the percentage of area occupied by VGAT puncta and VGAT/ gephyrin puncta in DG of 4.5- to 5.5-month-old male mice (Martinez-Cue et al., 2013). Differences in experimental methods, hippocampal subregions, age, or sex could account for these divergent results. On the other hand, very little is known about how E/l is affected across different brain regions or ages in Ts65Dn mice. Possibly, the $E / l$ imbalance could arise from alterations in excitation, inhibition, or both and may be continuously changing as a result of synaptic plasticity, leading to region-specific dysfunction (Bartley et al., 2015).

Interestingly, EE-EGCG-treated Ts65Dn mice showed normal density and size of VGLUT1 puncta, and as a consequence, the balance of excitatory and inhibitory puncta in DG and in CA1 was also in the normal ranges. That the treatment restores the density and size of VGLUT1 puncta is consistent with the treatment effect on the density of dendritic spines. Excitatory synapses comprise a presynaptic terminal with abundant synaptic vesicles containing glutamate, in association with dendritic spine heads acting as a postsynaptic element. Thus, our results suggest that combined treatment with EE-EGCG may increase excitatory synaptic connections.

These results are also consistent with the outcome of a recent phase II clinical trial with DS individuals in which a therapy combining cognitive training and EGCG normalized neuronal network functionality, as measured by functional MRI, and cortical excitability by transcranial magnetic stimulation (de la Torre et al., 2016).

Conversely, in WT mice EE-EGCG treatment reduced spine density in CA1, but not in the DG, and led to E/I imbalance in CA1, without significant changes in the DG. This deleterious effect could be explained by an overinhibition of Dyrk1A kinase activity in WT conditions, since it has been shown that DYRK1A haploinsufficiency is associated with neuroanatomical and neuroarchitectural defects in flies, mice, and humans. Indeed, mutant flies with reduced Dyrk1A expression present reductions in the volumes of the adult optic lobes and central brain hemispheres (Tejedor et al., 1995). Brains from Dyrk1A heterozygous mice are $\sim 30 \%$ smaller and have reduced size and weight in specific brain regions, along with reduced neuronal density in the superior colliculus and increased neuronal numbers in brain regions such as somatosensory and motor cortices (Fotaki et al., 2002), with significantly smaller and less complex basal dendritic arbors and reduced dendritic spine densities (Benavides-Piccione et al., 2005). In the hippocampus, Dyrk1A heterozygous mice show a significant reduction in hippocampal thickness, accompanied by decreases in cell number in CA1, CA2, CA3, and DG (Arqué et al., 2008). Humans with de novo heterozygous variants of DYRK1A also have congenital microcephaly, structural brain abnormalities, and intellectual disability (Møller et al., 2008; Ji et al., 2015).

Taken together, our results suggest that combined treatment with EE and EGCG is a potent cognitive enhancing intervention for DS. We demonstrated that EE-EGCG treatment-derived cognitive improvements are associated with neuromodulatory effects at the hippocampus that normalize defects in dendritic spine density and E/l synaptic puncta ratio. Overall results suggest that combined EE-EGCG treatment has the capacity to simultaneously target several abnormal processes underlying intellectual disability in DS which would be optimal for a disease-modifying intervention in this clinical population.

\section{References}

Altafaj X, Dierssen M, Baamonde C, Martí E, Visa J, Guimerà J, Oset M, González JR, Flórez J, Fillat C, Estivill X (2001) Neurodevelopmental delay, motor abnormalities and cognitive deficits in transgenic mice overexpressing Dyrk1A (minibrain), a murine model of Down's syndrome. Hum Mol Genet 10:1915-1924. Medline

Antonarakis SE, Lyle R, Dermitzakis ET, Reymond A, Deutsch S (2004) Chromosome 21 and down syndrome: from genomics to pathophysiology. Nat Rev Genet 5:725-738. CrossRef Medline

Antonova I, Arancio O, Trillat AC, Wang HG, Zablow L, Udo H, Kandel ER, Hawkins RD (2001) Rapid increase in clusters of presynaptic proteins at onset of long-lasting potentiation. Science 294:1547-1550. CrossRef Medline

Arqué G, Fotaki V, Fernández D, Martínez de Lagrán M, Arbonés ML, Dierssen M (2008) Impaired spatial learning strategies and novel object recognition in mice haploinsufficient for the dual specificity tyrosine-regulated kinase-1A (Dyrk1A). PLoS One 3:e2575. CrossRef Medline

Bain J, McLauchlan H, Elliott M, Cohen P (2003) The specificities of protein kinase inhibitors: an update. Biochem J 371:199-204. CrossRef Medline

Bamji SX, Rico B, Kimes N, Reichardt LF (2006) BDNF mobilizes synaptic vesicles and enhances synapse formation by disrupting cadherin-beta-catenin interactions. J Cell Biol 174:289-299. CrossRef Medline

Baroncelli L, Braschi C, Spolidoro M, Begenisic T, Maffei L, Sale A (2011) Brain plasticity and disease: a matter of inhibition. Neural Plast 2011:286073. CrossRef Medline

Bartley AF, Lucas EK, Brady LJ, Li Q, Hablitz JJ, Cowell RM, Dobrunz LE (2015) Interneuron transcriptional dysregulation causes frequency-dependent alterations in the balance of inhibition and excitation in hippocampus. J Neurosci 35:15276-15290. CrossRef Medline

Becker LE, Armstrong DL, Chan F (1986) Dendritic atrophy in children with Down's syndrome. Ann Neurol 20:520-526. CrossRef Medline

Begenisic T, Spolidoro M, Braschi C, Baroncelli L, Milanese M, Pietra G, Fabbri ME, Bonanno G, Cioni G, Maffei L, Sale A (2011) 
Environmental enrichment decreases GABAergic inhibition and improves cognitive abilities, synaptic plasticity, and visual functions in a mouse model of Down syndrome. Front Cell Neurosci 5:29. CrossRef

Belichenko PV, Kleschevnikov AM, Masliah E, Wu C, TakimotoKimura R, Salehi A, Mobley WC (2009) Excitatory-inhibitory relationship in the fascia dentata in the Ts65Dn mouse model of Down syndrome. J Comp Neur 512:453-466. CrossRef Medline

Belichenko PV, Masliah E, Kleschevnikov AM, Villar AJ, Epstein CJ, Salehi A, Mobley WC (2004) Synaptic structural abnormalities in the Ts65Dn mouse model of Down syndrome. J Comp Neur 480:281-298. CrossRef Medline

Benavides-Piccione R, Dierssen M, Ballesteros-Yáñez I, Martínez de Lagrán M, Arbonés ML, Fotaki V, DeFelipe J, Elston GN (2005) Alterations in the phenotype of neocortical pyramidal cells in the Dyrk1A+/- mouse. Neurobiol Dis 20:115-122. CrossRef Medline

Benjamini Y, Hochberg Y (1995) Controlling the false discovery rate: a practical and powerful approach to multiple testing. J R Stat Soc Ser B 57:289-300.

Bhattacharyya A, McMillan E, Chen SI, Wallace K, Svendsen CN (2009) A critical period in cortical interneuron neurogenesis in Down syndrome revealed by human neural progenitor cells. Dev Neurosci 31:497-510. CrossRef Medline

Bourne JN, Chirillo MA, Harris KM (2013) Presynaptic ultrastructural plasticity along $\mathrm{CA} 3 \rightarrow \mathrm{CA} 1$ axons during long-term potentiation in mature hippocampus. J Comp Neur 521:3898-3912. CrossRef Medline

Bozdagi O, Shan W, Tanaka H, Benson DL, Huntley GW (2000) Increasing numbers of synaptic puncta during late-phase LTP. Neuron 28:245-259. Medline

Brown MW, Aggleton JP (2001) Recognition memory: what are the roles of the perirhinal cortex and hippocampus? Nat Rev Neurosci 2. CrossRef

Brown MW, Warburton EC, Aggleton JP (2010) Recognition memory: material, processes, and substrates. Hippocampus 20:12281244. CrossRef Medline

Catuara-Solarz S, Espinosa-Carrasco J, Erb I, Langohr K, Notredame C, Gonzalez JR, Dierssen M (2015) Principal component analysis of the effects of environmental enrichment and (-)epigallocatechin-3-gallate on age-associated learning deficits in a mouse model of Down syndrome. Front Behav Neurosci 9:330. CrossRef

Chakrabarti L, Scafidi J, Gallo V, Haydar TF (2011) Environmental enrichment rescues postnatal neurogenesis defect in the male and female Ts65Dn mouse model of Down syndrome. Dev Neurosci 33:428-441. CrossRef Medline

Chapman RS, Hesketh LJ (2000) Behavioral phenotype of individuals with Down syndrome. Ment Retard Dev Disabil Res Rev 6:84-95. CrossRef Medline

Coussons-Read ME, Crnic LS (1996) Behavioral assessment of the Ts65Dn mouse, a model for Down syndrome: altered behavior in the elevated plus maze and open field. Behav Genet. 1996 Jan; 26(1):7-13.

De la Torre R, et al. (2014) Epigallocatechin-3-gallate, a DYRK1A inhibitor, rescues cognitive deficits in Down syndrome mouse models and in humans. Mol Nutr Food Res 58:278-288. CrossRef Medline

de la Torre R, et al. (2016) Safety and efficacy of cognitive training plus epigallocatechin-3-gallate in young adults with Down's syndrome (TESDAD): a double-blind, randomised, placebo-controlled, phase 2 trial. Lancet Neurol 15:801-810. CrossRef Medline

de Sola S, de la Torre R, Sánchez-Benavides G, Benejam B, CuencaRoyo A, Del Hoyo L, Rodríguez J, Catuara-Solarz S, SanchezGutierrez J, Dueñas-Espin I, Hernandez G, Peña-Casanova J, Langohr K, Videla S, Blehaut H, Farre M, Dierssen M (2015) A new cognitive evaluation battery for Down syndrome and its relevance for clinical trials. Front Psychol 6:708. CrossRef Medline

Demas G, Nelson RJ, Krueger BK, Yarowsky PJ (1996) Spatial memory deficits in segmental trisomic Ts65Dn mice. Behav Brain Res 82:85-92.
Deng W, Aimone JB, Gage FH (2010) New neurons and new memories: how does adult hippocampal neurogenesis affect learning and memory?. Nat Rev Neurosci 11:339-350. CrossRef Medline

Dias GP, Cavegn N, Nix A, do Nascimento Bevilaqua MC, Stangl D, Zainuddin MSA, Nardi AE, Gardino PF, Thuret S (2012) The role of dietary polyphenols on adult hippocampal neurogenesis: molecular mechanisms and behavioural effects on depression and anxiety. Oxid Med Cell Longev 2012:541971. CrossRef

Dickhaus T (2012) Multiple Comparisons Using R by Bretz, F., Hothorn, T., and Westfall, P. Biometrics 68:995-995. CrossRef

Dierssen M (2003) Alterations of neocortical pyramidal cell phenotype in the Ts65Dn mouse model of Down syndrome: effects of environmental enrichment. Cereb Cortex 13:758-764. Medline

Dierssen M (2012) Down syndrome: the brain in trisomic mode. Nat Rev Neurosci 13:844-858. CrossRef Medline

Escorihuela RM, Fernández-Teruel A, Vallina IF, Baamonde C, Lumbreras MA, Dierssen M, Tobeña A, Flórez J (1995) A behavioral assessment of Ts65Dn mice: a putative Down syndrome model. Neurosci Lett 199:143-146. Medline

Escorihuela RM, Vallina IF, Martánez-Cué C, Baamonde C, Dierssen M, Tobeña A, Flórez J, Fernóndez-Teruel A. (1998) Impaired shortand long-term memory in Ts65Dn mice, a model for Down syndrome. Neurosci Lett. 15;247(2-3):171-174.

Fernandez F, Morishita W, Zuniga E, Nguyen J, Blank M, Malenka RC, Garner CC (2007) Pharmacotherapy for cognitive impairment in a mouse model of Down syndrome. Nat Neurosci 10:411-413. CrossRef Medline

Ferrer I, Gullotta F (1990) Down's syndrome and Alzheimer's disease: dendritic spine counts in the hippocampus. Acta Neuropathol 79:680-685. Medline

Fotaki V, Dierssen M, Alca S, Martínez S, Casas C, Visa J, Soriano E, Estivill X, Arbone ML (2002) Dyrk1A haploinsufficiency affects viability and causes developmental delay and abnormal brain morphology in mice. Mol Cell Biol 22:6636-6647. CrossRef

Golabek A, Jarz K, Palminiello S, Walus M, Rabe A, Albertini G (2011) Brain plasticity and environmental enrichment in Ts65Dn mice, an animal model for Down syndrome. In: Neurocognitive rehabilitation of Down syndrome (Rondale JA, Perera J, Spiker D, eds), 71-84. Cambridge University Press: Cambridge, UK.

Greenacre, MJ (2010) Biplots in Practice. Bilbao: Fundacion BBVA.

Hand DJ, Taylor CC (1987) Multivariate analysis of variance and repeated measures: a practical approach for behavioural scientists. CRC Press: Boca Raton, FL.

Harris KM, Sultan P (1995) Variation in the number, location and size of synaptic vesicles provides an anatomical basis for the nonuniform probability of release at hippocampal CA1 synapses. Neuropharmacology 34:1387-1395. Medline

Harrison FE, Hosseini AH, McDonald MP (2009) Endogenous anxiety and stress responses in water maze and Barnes maze spatial memory tasks. Behav Brain Res 198:247-251. CrossRef Medline

Henningsen A (2011) censReg: censored regression (Tobit) models. $\mathrm{R}$ package version 0.5. Available at https://cran.r-project.org/web/ packages/censReg/index.html.

Hothorn T, Bretz F, Westfall P (2008) Simultaneous inference in general parametric models. Biometrical J 50:346-363. CrossRef Medline

Hyde LA, Crnic LS (2002) Reactivity to object and spatial novelty is normal in older Ts65Dn mice that model Down syndrome and Alzheimer's disease. Brain Res. 26;945(1):26-30.

$\mathrm{Ji}$ J, et al. (2015) DYRK1A haploinsufficiency causes a new recognizable syndrome with microcephaly, intellectual disability, speech impairment, and distinct facies. Eur J Hum Genet 23:1473-1481. CrossRef Medline

Jia N, Han K, Kong J-J, Zhang X-M, Sha S, Ren G-R, Cao Y-P (2013) (-)-Epigallocatechin-3-gallate alleviates spatial memory impairment in APP/PS1 mice by restoring IRS-1 signaling defects in the hippocampus. Mol Cell Biochem 380:211-218. CrossRef Medline Khoshnood B, Greenlees R, Loane M, Dolk H (2011) Paper 2: EUROCAT public health indicators for congenital anomalies in Eu- 
rope. Birth Defects Res A Clin Mol Teratol 91: Suppl 1:S16-S22. CrossRef Medline

Kleschevnikov AM, Belichenko PV, Faizi M, Jacobs LF, Htun K, Shamloo M, Mobley WC (2012) Deficits in cognition and synaptic plasticity in a mouse model of Down syndrome ameliorated by GABAB receptor antagonists. J Neurosci 32:9217-9227. CrossRef

Lê S, Josse J, Husson F (2008) FactoMineR: an R package for multivariate analysis. J Stat Softw 25:1-18. CrossRef

Leger M, Quiedeville A, Bouet V, Haelewyn B, Boulouard M, Schumann-Bard P, Freret T (2013) Object recognition test in mice. Nat Protoc 8:2531-2537. CrossRef Medline

Li Q, Zhao HF, Zhang ZF, Liu ZG, Pei XR, Wang JB, Cai MY, Li Y (2009a) Long-term administration of green tea catechins prevents age-related spatial learning and memory decline in C57BL/6 J mice by regulating hippocampal cyclic AMP-response element binding protein signaling cascade. Neuroscience 159:1208-1215.

Li Q, Zhao HF, Zhang ZF, Liu ZG, Pei XR, Wang JB, Li Y (2009b) Long-term green tea catechin administration prevents spatial learning and memory impairment in senescence-accelerated mouse prone- 8 mice by decreasing Abeta1-42 oligomers and upregulating synaptic plasticity-related proteins in the hippocampus. Neuroscience 163:741-749.

Lott IT, Dierssen M (2010) Cognitive deficits and associated neurological complications in individuals with Down's syndrome. Lancet Neurol 9:623-633. CrossRef Medline

Maei HR, Zaslaversusky K, Teixeira CM, Frankland PW (2009) What is the most sensitive measure of water maze probe test performance? Front Integr Neurosci 3:4CrossRef Medline

Mahoney G, Wheeden CA, Perales F (2004) Relationship of preschool special education outcomes to instructional practices and parent-child interaction. Res Dev Disabil 25:539-558. CrossRef Medline

Martinez de Lagran M, Benavides-Piccione R, Ballesteros-Yañez I, Calvo M, Morales M, Fillat C, Defelipe J, Ramakers GJ, Dierssen M (2012) Dyrk1A influences neuronal morphogenesis through regulation of cytoskeletal dynamics in mammalian cortical neurons. Cereb Cortex 22:2867-2877. CrossRef Medline

Martínez-Cué C, Baamonde C, Lumbreras M, Paz J, Davisson MT, Schmidt C, Dierssen M, Flórez J (2002) Differential effects of environmental enrichment on behavior and learning of male and female Ts65Dn mice, a model for Down syndrome. Behav Brain Res 134:185-200. Medline

Martinez-Cue C, Martinez P, Rueda N, Vidal R, Garcia S, Vidal V, Corrales A, Montero JA, Pazos A, Florez J, Gasser R, Thomas AW, Honer M, Knoflach F, Trejo JL, Wettstein JG, Hernandez M-C (2013) Reducing GABAA 5 receptor-mediated inhibition rescues functional and neuromorphological deficits in a mouse model of Down syndrome. J Neurosci 33:3953-3966. CrossRef

Møller RS, Kübart S, Hoeltzenbein M, Heye B, Vogel I, Hansen CP, Menzel C, Ullmann R, Tommerup N, Ropers $\mathrm{H}-\mathrm{H}$, Tümer Z, Kalscheuer VM (2008) Truncation of the Down syndrome candidate gene DYRK1A in two unrelated patients with microcephaly. Am J Hum Genet 82:1165-1170. CrossRef Medline

Nadel L (2003) Down's syndrome: a genetic disorder in biobehavioral perspective. Genes Brain Behav 2:156-166. Medline

Netzer WJ, Powell C, Nong Y, Blundell J, Wong L, Duff K, Flajolet M, Greengard P (2010) Lowering beta-amyloid levels rescues learning and memory in a Down syndrome mouse model. PLoS One 5:e10943CrossRef Medline

Ortiz-López L, Márquez-Valadez B, Gómez-Sánchez A, Silva-Lucero MDC, Torres-Pérez M, Téllez-Ballesteros RI, Ichwan M, MerazRíos MA, Kempermann G, Ramírez-Rodríguez GB (2016) Green tea compound epigallo-catechin-3-gallate (EGCG) increases neuronal survival in adult hippocampal neurogenesis in vivo and in vitro. Neuroscience 322:208-220. CrossRef

Parker SE, Mai CT, Canfield MA, Rickard R, Wang Y, Meyer RE, Anderson P, Mason CA, Collins JS, Kirby RS, Correa A (2010) Updated national birth prevalence estimates for selected birth defects in the United States, 2004-2006. Birth. Defects Res A Clin Mol Teratol 88:1008-1016. CrossRef Medline
Paxinos G, Franklin K (2012) The mouse brain in stereotaxic coordinates. Academic Press: New York.

Pennington BF, Moon J, Edgin J, Stedron J, Nadel L (2003) The neuropsychology of down syndrome: evidence for hippocampal dysfunction. Child Dev 74:75-93. Medline

Pinheiro J, Bates D, DebRoy S, Sarkar D, R Core Team (2016) \{nlme\}: Linear and Nonlinear Mixed Effects Models. Available at https:// cran.r-project.org/web/packages/nlme/index.html.

Pons-Espinal M, Martinez de Lagran M, Dierssen M (2013) Environmental enrichment rescues DYRK1A activity and hippocampal adult neurogenesis in TgDyrk1A. Neurobiol Dis 60:18-31. CrossRef Medline

Ramírez-Rodríguez G, Ocaña-Fernández MA, Vega-Rivera NM, Torres-Pérez OM, Gómez-Sánchez A, Estrada-Camarena E, OrtizLópez L (2014) Environmental enrichment induces neuroplastic changes in middle age female Balb/c mice and increases the hippocampal levels of BDNF, p-Akt and p-MAPK1/2. Neuroscience 260:158-170. CrossRef Medline

Reeves RH, Irving NG, Moran TH, Wohn A, Kitt C, Sisodia SS, Schmidt C, Bronson RT, Davisson MT (1995) A mouse model for Down syndrome exhibits learning and behaviour deficits. Nat Genet 11:177-184. CrossRef Medline

Reynolds GP, Warner CE (1988) Amino acid neurotransmitter deficits in adult Down's syndrome brain tissue. Neurosci Lett 94:224-227. Medline

Risser D, Lubec G, Cairns N, Herrera-Marschitz M (1997) Excitatory amino acids and monoamines in parahippocampal gyrus and frontal cortical pole of adults with Down syndrome. Life Sci 60: 1231-1237. Medline

Sale A, Berardi N, Maffei L (2014) Environment and brain plasticity: towards an endogenous pharmacotherapy. Physiol Rev 94:189234. CrossRef Medline

Seidl R, Cairns N, Lubec G (2001) The brain in Down syndrome. J Neural Transm Suppl 247-261.

Sham PC, Purcell SM (2014) Statistical power and significance testing in large-scale genetic studies. Nat Rev Genet 15:335-346. CrossRef Medline

Shichiri M, Yoshida Y, Ishidaa N, Hagihara Y, Iwahashi H, Tamai H, Niki E (2011) $\alpha$-Tocopherol suppresses lipid peroxidation and behavioral and cognitive impairments in the Ts65Dn mouse model of Down syndrome. Free Radical Biology and Medicine Volume 50, Issue 12, 15 June 2011, Pages 1801-1811.

Souchet B, Guedj F, Penke-Verdier Z, Daubigney F, Duchon A, Herault Y, Bizot J-C, Janel N, Créau N, Delatour B, Delabar JM (2015) Pharmacological correction of excitation/inhibition imbalance in Down syndrome mouse models. Front Behav Neurosci 9:267. CrossRef

Tejedor F, Zhu XR, Kaltenbach E, Ackermann A, Baumann A, Canal I, Heisenberg M, Fischbach KF, Pongs O (1995) Minibrain: a new protein kinase family involved in postembryonic neurogenesis in Drosophila. Neuron 14:287-301. Medline

Tsien JZ, Huerta PT, Tonegawa S (1996) The essential role of hippocampal CA1 NMDA receptor-dependent synaptic plasticity in spatial memory. Cell 87:1327-1338. Medline

Vock DM, Davidian M, Tsiatis AA, Muir AJ (2012) Mixed model analysis of censored longitudinal data with flexible random-effects density. Biostatistics 13,61-73. CrossRef

Whishaw IQ, Jarrard LE (1996) Evidence for extrahippocampal involvement in place learning and hippocampal involvement in path integration. Hippocampus 6:513-524. CrossRef Medline

Wickham H (2009) ggplot2: elegant graphics for data analysis. Springer: New York.

Xie W, Ramakrishna N, Wieraszko A, Hwang Y-W (2008) Promotion of neuronal plasticity by (-)-epigallocatechin-3-gallate. Neurochem Res 33:776-783. CrossRef Medline

Young D, Lawlor PA, Leone P, Dragunow M, During MJ (1999) Environmental enrichment inhibits spontaneous apoptosis, prevents seizures and is neuroprotective. Nat Med 5:448-453. CrossRef Medline 